\title{
Effects of an internal sulfate attack and an alkali-aggregate reaction in a concrete dam
}

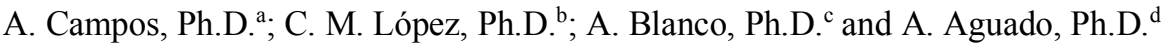 \\ ${ }^{a}$ Universidade Estadual de Londrina, Rodovia Celso Garcia Cid, Km 380, s/n - Campus Universitário, Londrina - PR, \\ 86057-970, Brazil, andre.moura@uel.br \\ bUniversitat Politècnica de Catalunya, Jordi Girona 1-3, 08034 Barcelona, Spain, carlos.maria.lopez@upc.edu \\ ${ }^{c}$ Loughborough University, Epinal Way, LE11 3TU Loughborough, United Kingdom, a.blanco-alvarez@lboro.ac.uk \\ (corresponding author) \\ ${ }^{\mathrm{d}}$ Universitat Politècnica de Catalunya, Jordi Girona 1-3, 08034 Barcelona, Spain, antonio.aguado@upc.edu
}

\begin{abstract}
The alkali-aggregate reaction and the internal sulfate attack are two chemical reactions that lead to expansions in concrete structures. The former is one of the main causes of expansions in concrete dams and has been extensively reported in the literature, whereas the latter is less common and, thus, less studied. The confluence of both reactions in one structure is highly unlikely but still possible as shown by the case of the dam studied in this paper. This gravity dam exhibits significantly high non-recoverable displacements that may only be justified by the superposition of both phenomena. This paper focuses on the study of a concrete dam whose diagnosis hypotheses have changed throughout the years according to evolution of the behavior observed. The hypotheses proposed in the study are validated by conducting numerical analyses through 3D and 2D finite element models. The results confirmed the diagnosis proposed and the capability of the model to reproduce the behavior of the dam.
\end{abstract}

Keywords: internal sulfate attack, alkali-aggregate reaction, concrete dam, finite element

\section{INTRODUCTION}

Hydraulic infrastructures have a major economic influence in the environment and the society given their ability to transform the territory. Concrete dams are the greatest example of the repercussion in the territory of large infrastructures. Despite concrete dams are built to endure high external loads and be durable, pathologies may arise during their service life. In some cases, the pathology may compromise the safety of the structure, but often it only affects the daily operations of the dam.

Expansive reactions are a common phenomenon in concrete dams. The expansions usually generate internal stresses, cracking and non-recoverable displacement that may alter the normal functioning. Identifying the causes and determining the extent of the damage is essential to conduct rehabilitation tasks and avoid further degradation of the dam. The most common expansive reactions in concrete dams are alkali-aggregate (AAR) and, in particular, the alkalisilica reaction (ASR) that has been extensively studied and reported in the literature. The internal sulfate attack (ISA) is another type of expansive reaction that is less frequent.

The ASR has been studied for 70 years [1-4] and occurs in the presence of aggregates that contain amorphous and cryptocrystalline silica. Examples of such aggregates are glassy volcanic rocks and tuff, rocks containing opal and other rocks with high silica content. The reaction generates a gel that absorbs humidity and expands. The expansive mechanism of the ASR may be described, in simplified way, as a two-stage reaction between the alkalis (sodium and potassium) of the cement and the reactive silica of the aggregates.

A certain type of ISA may be caused by the use of aggregates containing iron sulfides (pyrrhotite and pyrite) that oxidize inside the concrete releasing sulfates [5-7]. The sulfates, in turn, react with the cement paste components (portlandite and tricalcium aluminate) generating potentially expansive secondary ettringite [8]. The evolution of the ISA in concrete dams depends on the 
oxygen concentration and humidity, which varies from the upstream to the downstream faces. As a result, a clear difference takes place between the areas close to the oxidant agent (the oxygen in the atmosphere) and the rest of the dam, thus leading to differential deformations and internal stresses that are higher in the downstream face due to the higher concentration of oxygen.

References of concrete dams experiencing separately ISA or AAR may be found in the literature; however, cases where both reactions occurred in the same dam are unusual (some cases have been diagnosed in the Spanish Pyrenees) and scarcely documented.

In fact, in most cases the report the combination of AAR with a certain type of ISA known as delayed ettringite formation (DEF). DEF is associated to the decomposition of primary ettringite, which is not stable at high temperatures (generally over 70 Celsius degrees), into monosulfate and gypsum. After the hardening, the temperature in concrete decreases and the secondary ettringite is formed resulting in expansions $[9,10]$. Usually, the studies about these combined phenomena deal with the microstructure and experimental data [11, 12], without considering the influence in the structural damage.

In this context, evaluating the rare confluence of AAR and ISA gains special relevance since it may yield further information on the degradation processes. Additionally, if numerical tools are used to validate the diagnosis hypotheses and justify the structural behavior observed in the dam, the study may serve as an example for future diagnosis.

Modelling expansive reactions in concrete dams may help to estimate the long-term behavior of the structure and define the rehabilitation strategy. The studies in the literature mostly correspond to the modelling of AAR, to a lesser extent to the external sulfate attack (ESA) and those related to modelling ISA are almost non-existent. Generally, AAR models may be grouped in three categories according to their level of approximation [13]: micro, meso and macro scale. The models at a micro-scale [14-17] and a meso-scale [18-21] represent explicitly the heterogeneity of concrete and their goal is to elucidate the underlying mechanisms of the expansions. Therefore, these levels of approximations are less relevant in a structural analysis such as in the case of the present study.

The models at a macro-scale are generally implemented in finite elements (FEM) and consider concrete as a homogeneous material combining chemical aspects and their mechanical effects. According to Saouma [13] can be distinguished:

- Empirical models where ASR expansions are estimated through kinetic laws (depending on chemical reactions, stresses, temperature and relative humidity $(\mathrm{RH})$ ) that are imposed in each point of the mesh (analogously to thermal expansions) [22-25]

- Coupled chemo-mechanical models that account for the time-depending nature (kinetics) of chemical reactions (due to the diffusion processes) in the mechanical response [26-32]

Generally, modelling chemical reactions requires considering the transport processes involved, thus leading to reaction-diffusion systems. These systems allow evaluating how the concentration of one or more substances distributed in the space change under the influence of the chemical reactions (locally transforming substances in others) and the diffusion (transporting substances in the space). Fick's law is usually used to describe the diffusion processes of the chemical components in pervious materials. In the case of ISA due to oxidation of the iron sulfides in the aggregate, the reaction depends on the transport of oxygen from the outside to the inside of the concrete matrix.

The paper presents the real case of a concrete dam monitored for more than 25 years with cracking and significant non-recoverable displacements (in some blocks up to $200 \mathrm{~mm}$ ). The early 
diagnosis suggested an ISA; however, long-term monitoring has revealed that the ISA alone could not justify the displacements registered. The aim of the study is to define a conclusive diagnosis.

For that, the diagnosis hypotheses are reformulated assuming the confluence of an ISA and AAR developed at different stages of the service life. Subsequently, the structural behavior is simulated through 3D and 2D finite element models. The present study applies the kinetic model proposed by Ulm et al. [26] to simulate the expansions due to AAR (in AAR, the transport models used in the literature are mainly at a micro-scale). The ISA is considered by means of a reaction-diffusion model proposed by the authors for concrete dams in [33]. The 2D non-linear model includes joints to represent the cracks observed in the structure, applying the formulation proposed by Carol et al. [34]. This approach allows assessing the contribution of the damage and cracking on the displacements registered. Finally, the new hypotheses are numerically and experimentally validated.

\section{DESCRIPTION OF THE DAM}

\subsection{General characteristics}

The concrete dam studied is a gravity dam located in Pyrinees in the northeast of Spain and built between 1968 and 1971. The dam presents a straight form in the ground plant with a crest length of $102.4 \mathrm{~m}$ and a height of $28.9 \mathrm{~m}$ (the lowest level of the foundation is at $1327.7 \mathrm{~m}$ and the crest is at $1356.6 \mathrm{~m}$ above sea level, respectively). The dam is divided into seven blocks as shown in Fig. 1, which are $15.0 \mathrm{~m}$ wide with the exception of block 1 that is $12.4 \mathrm{~m}$ wide. The dam presents one gallery at level $1335.3 \mathrm{~m}$. The reservoir, which exhibits a capacity of $0.33 \mathrm{hm}^{3}$, was filled for the first time in November 1971.

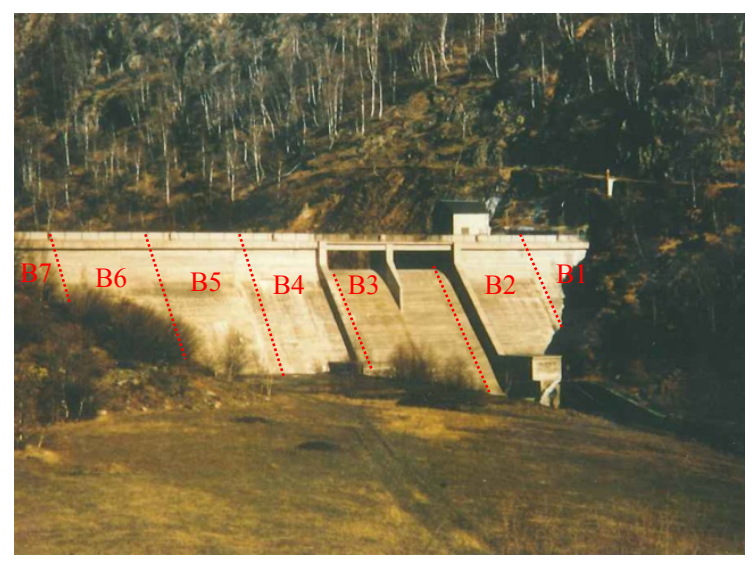

Fig.1. View of the dam from downstream.

Regarding the geological characteristics of the region, the dam is located in an area where the predominant rocks are slate and phyllites. The use of this type of aggregate in the concrete for dam construction was confirmed by the historical records on the construction procedure and by the microstructural analyses performed.

\subsection{Current state and behavior}

The original instrumentation in the dam consisted of a pendulums system that was complemented in 1981 with the equipment to measure vertical and horizontal displacements at the crest of the dam and at the gallery. The data registered between 1981 and 1986 allowed detecting an abnormal behavior reflected by horizontal non-recoverable displacements towards upstream that has increased through the years. Fig. $2 \mathrm{a}$ and Fig. $2 \mathrm{~b}$ show the evolution of the horizontal and vertical displacements at the crest of the dam for each block since 1981. 
The values in Fig. 2 reveal that the non-recoverable displacements have increased significantly in the past 30 years. Notice that block B5 presents a horizontal displacement of $225 \mathrm{~mm}$ towards upstream in 2011 and a vertical displacement of $95 \mathrm{~mm}$, which are remarkable values for a dam that is $28.9 \mathrm{~m}$ high. The curves also show cyclic displacements as a result of the variations in temperature and level of the reservoir that are significantly lower than the non-recoverable displacement accumulated throughout the years. In the gallery, no significant displacements were observed up to 1995, when vertical non-recoverable displacements were detected. However, the magnitude of these displacements is smaller than at the crest of the dam.

Fig. $2 \mathrm{c}$ and Fig. $2 \mathrm{~d}$ show the evolution of the horizontal and vertical displacements, respectively, in each block since 1986 to 2011. The maximum horizontal displacements occur in blocks B4 and $\mathrm{B} 5$ and tend to decrease in the blocks close to the abutments. The vertical displacements are similar in the blocks with approximately the same height (B2, B4 and B5).
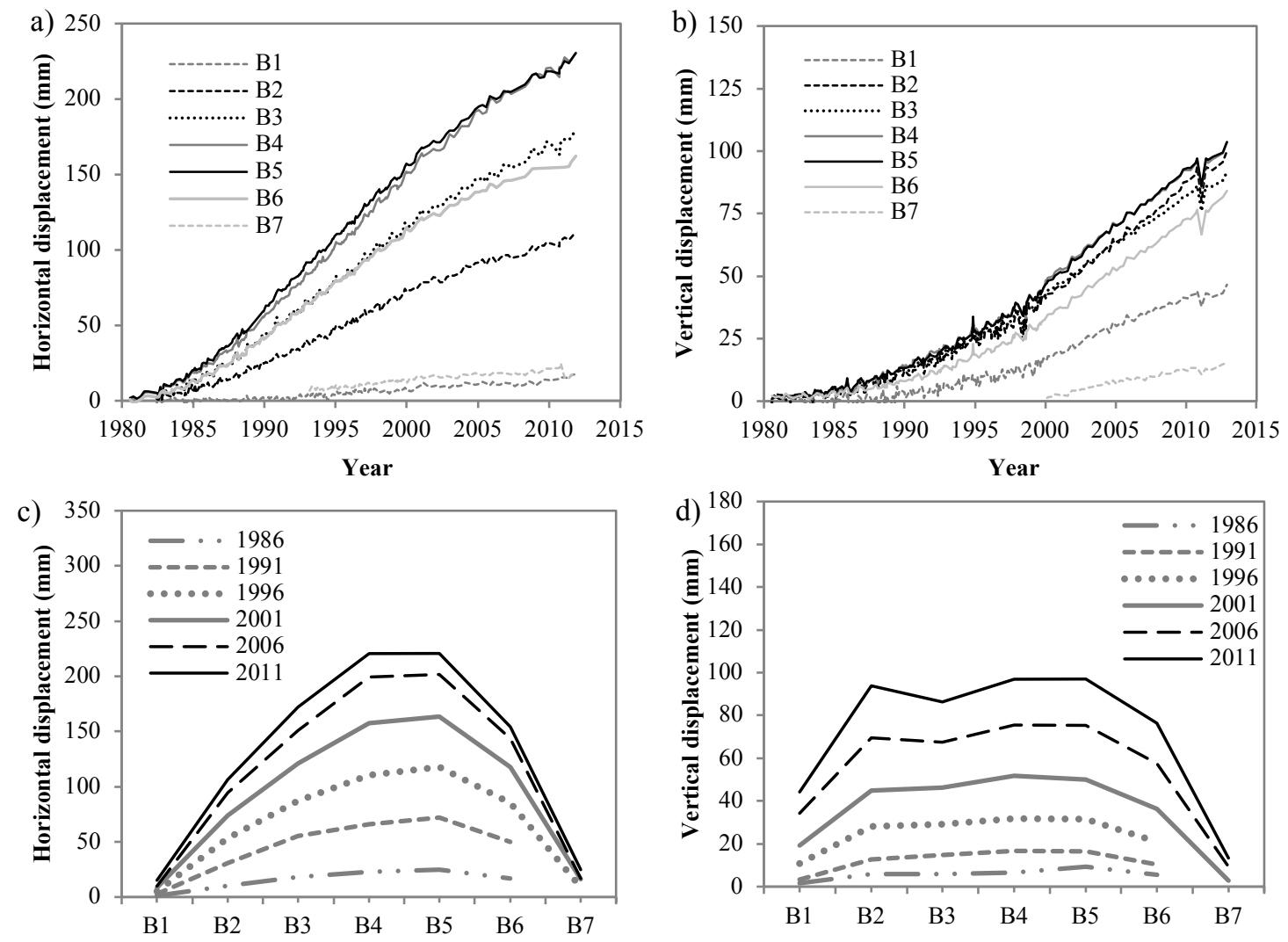

Fig. 2. Evolution of: a) horizontal and b) vertical displacements at the crest of the dam, c) horizontal and d) vertical displacements in each block.

Besides the non-recoverable displacements, other proofs were observed in the dam that suggest a pathology that may be affecting the performance of the dam, particularly map cracking and an ochre shading. These evidences are observed in the dam and in other auxiliary elements. Fig. 3 shows areas with map cracking and ochre shading in several areas of the downstream face. 

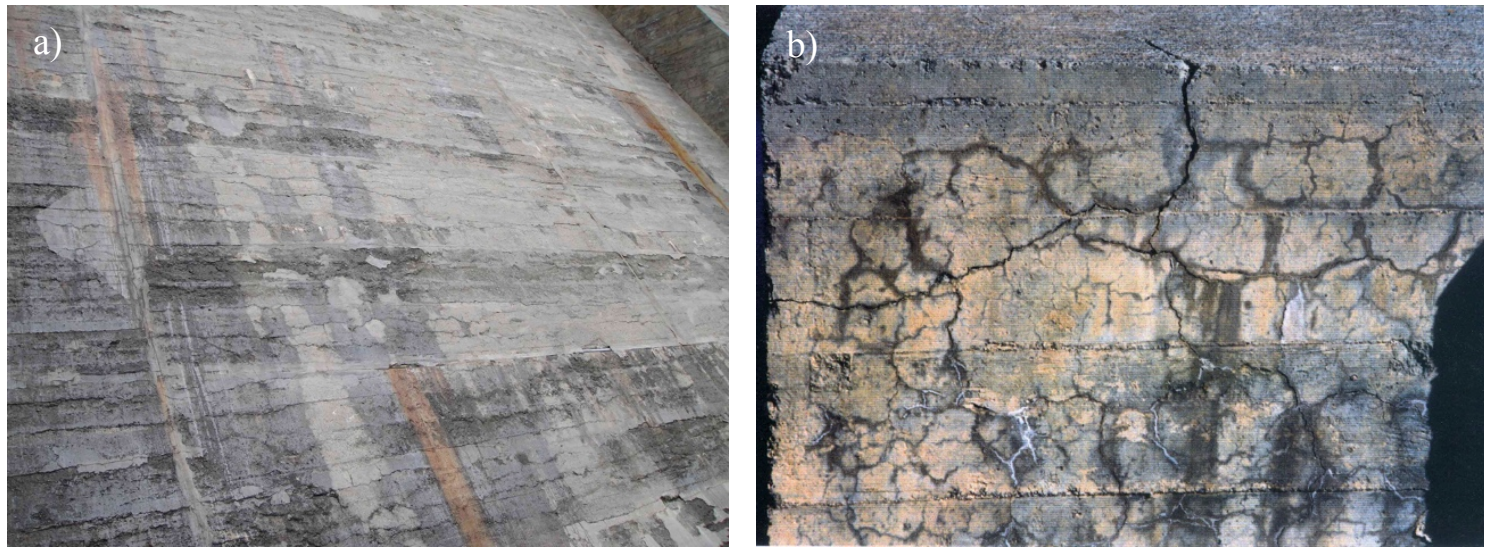

Fig. 3. Map cracking and ochre shading: a) downstream face and b) auxiliary elements.

The phenomena described (non-recoverable displacements, map cracking and ochre shading) are indicators of a possible expansive reaction in the concrete of the dam.

\section{EVOLUTION OF THE DIAGNOSIS}

\subsection{Previous studies}

The first experimental study on the behavior observed in the dam was conducted in 1987. The study involved aggregate and concrete cores characterization through visual inspection, X-ray diffraction (XRD) and microscopy. The analyses performed revealed the presence of iron sulfides in the aggregates and secondary ettringite in the interface of the aggregate and the cement paste. Gel from an alkali-aggregate reaction (AAR) was also found in the concrete of the dam, however it was isolated and in small amounts. This product of the AAR did not justify the magnitude of the displacements observed in the dam. Therefore, at that time, the main cause for the abnormal behavior of the dam was considered to be an internal sulfate attack (ISA) due to the oxidation of the iron sulfides in the aggregates.

Subsequently, in 1993 another experimental program was planned to further evaluate the origin of the increasing non-recoverable displacements registered at the dam. Again, aggregates and concrete cores were analyzed through several techniques. The visual inspection allowed identifying clear sulfide seams in the rock, as shown in Fig. 4a.

An extensive study was conducted on the aggregates obtained from crushing the blocks extracted from the stone quarries close to the dam. Fig. $4 \mathrm{~b}$ shows the aggregate samples stored in bags outside, which exhibit rust stains due to the presence of pyrrhotite in the aggregates.
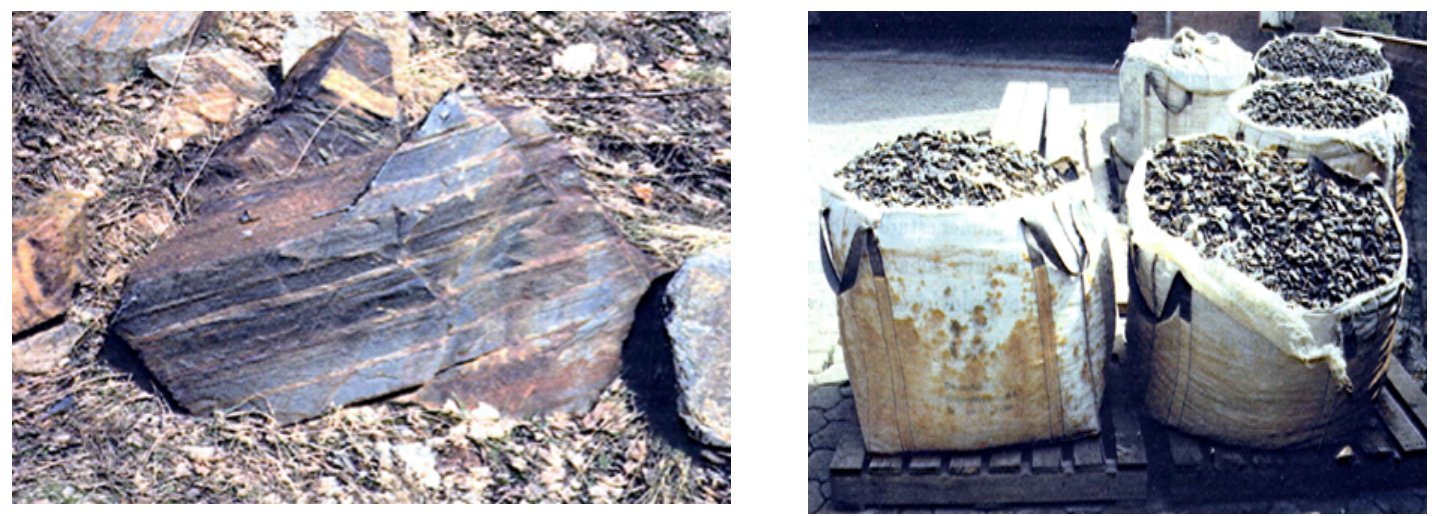

Fig. 4. Sulfide seams in rock samples: a) detail of slate and b) aggregate for testing. 
The chemical analysis of the rock confirmed the presence of iron sulfides, particularly phyrrotite, with sulfate concentrations around $1.98 \%$. In the concrete cores, significant amounts of ettringite were found mainly in the interface of the aggregate and the paste. Based on the experimental studies and on the displacements registered up to 1993, it was again suggested that the main cause was an ISA. However, given that products of an AAR were also detected, it was also suggested that there might be a secondary expansive reaction (AAR) that may overlap at some point with the ISA.

\subsection{Current hypothesis}

The significant increase of the non-recoverable displacements detected from 1993 to 2011 (see Fig. 2) and the presence of new cracks in the dam lead to another experimental study to evaluate the evolution of the behavior. Notice that in 1993 the horizontal and vertical displacement at the crest of the dam in block B5 were $82 \mathrm{~mm}$ and $18 \mathrm{~mm}$, respectively; however, in 2011 these values are $225 \mathrm{~mm}$ and $95 \mathrm{~mm}$, respectively, as previously mentioned. In addition, the displacements at the gallery in block B5 were negligible, whereas in 2011 the vertical displacements are $10 \mathrm{~mm}$. The vertical shafts of the pendulum system did not exhibit visible cracks in 1991, however since 2009 several cracks are observed (see Fig. 20 in subsequent sections).

The studies performed reveal that the horizontal displacements of the dam are caused by the expansion of concrete due to ASI. This type of expansive reaction requires oxygen to occur and, for that reason, the increment in volume is concentrated in the faces in contact with oxygen. Such expansion leads to displacements at the crest of the dam towards upstream. However, this reaction does not explain the displacements registered in the gallery, which is located at a low level and near the reservoir (the upstream face). Such location would involve high humidity and low oxygen transportation. Furthermore, the magnitude of the vertical displacements at the crest of the dam in 2011 cannot be the result of only an ISA.

For this reason, another experimental study was conducted in 2011 (see Fig. 18 in section 6.2) involving scanning electron microscopy (SEM) that confirmed the presence of the two expansive reactions (ISA and AAR) in the concrete of the dam. According to the images obtained from SEM, the ISA occurred first and then the AAR appeared, developing at a slower pace.

The current hypothesis based on the observation and study of the behavior of the dam over 25 years is that two expansive reactions coexist: one of them is global (AAR) and the other (ISA) affects the region in contact with oxygen, in other words, areas where the water may contain higher contents of oxygen to initiate the primary reaction of the phyrrotite oxidation such as the downstream face. The expansion resulting from both reactions could explain the high horizontal displacements registered due to ISA, the elevation of the gallery (this measurement was key to determine the magnitude of the AAR) and the high vertical displacements (up to $95 \mathrm{~mm}$ ) at the crest of the dam.

The damage and the cracking observed in the dam could also have affected the behavior of the dam and the magnitude of the displacements registered. This assumption will be evaluated in subsequent sections through numerical modelling.

\section{NUMERICAL MODELLING}

Gravity dams with a straight form are generally satisfactorily modelled through 2D finite element models in plain-strain conditions. However, given the magnitude of displacements registered at the central blocks of the dam, a more detailed analysis is required. Notice that the expansions at the central blocks may lead to longitudinal compression in the structure and to an arch effect that would contribute to increase the displacements. Therefore, a 3D finite element model was developed to study the complete dam and a 2D model of block 5 was also implemented to specifically evaluate the behavior of that block. 


\subsection{Description of the FE Model}

\subsubsection{D model}

The geometry of the 3D model, the generation of the FE mesh and the representation of the results was conducted with the software $G i D$, whereas the calculations were performed by means of the FE code DRAC, developed at the Department of Civil and Environmental Engineering at the Universitat Politècnica de Catalunya (UPC). Fig. 5a shows the 3D geometry of the dam from downstream and the FE mesh. Fig. 5b presents the interfaces between the blocks of the dam and between the dam and the surrounding soil.
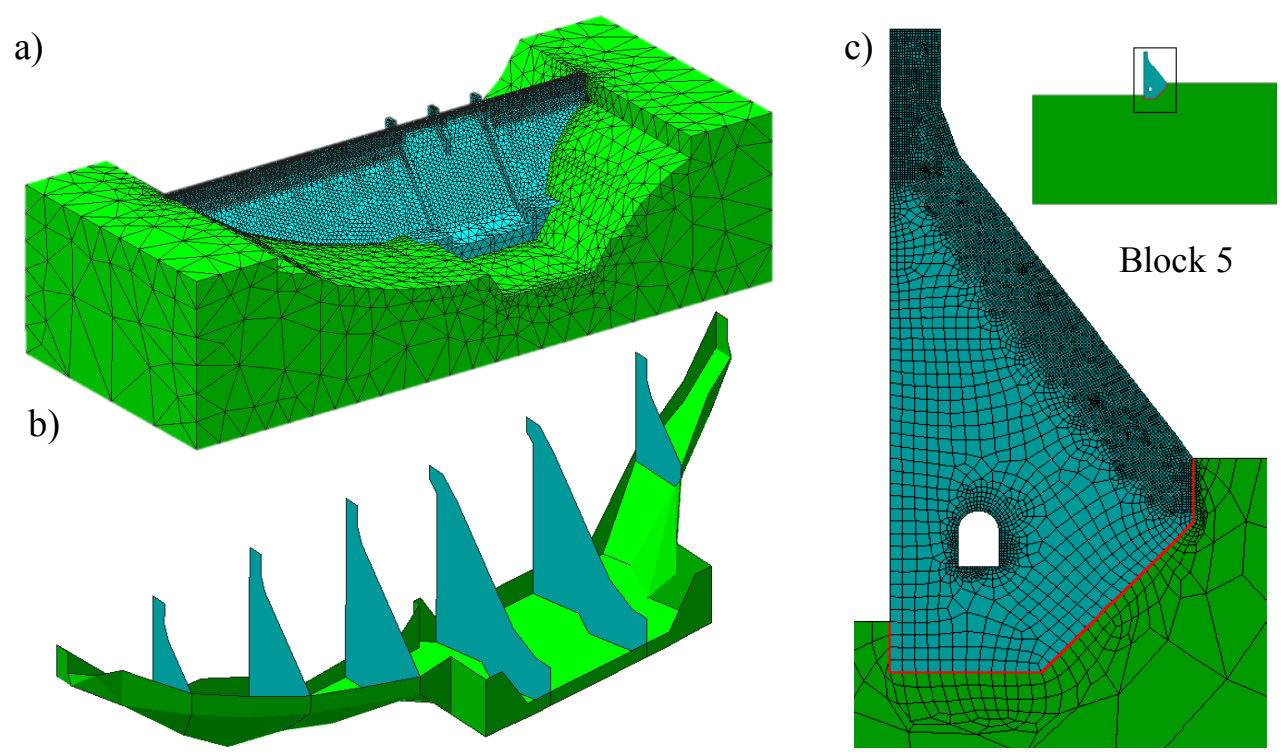

Fig. 5. a) Geometry of the 3D model and FE mesh, b) interfaces in the 3D model and c) geometry of the 2D model and FE mesh.

The FE mesh is denser in the downstream face and in the upper part of the upstream face of the dam, which correspond to the areas exposed to the ISA. The mesh consists of 56920 linear tetrahedron elements and 3349 triangular interface elements.

\subsubsection{D model}

Fig. 5c presents the finite element mesh created for modeling block 5 with a higher density of elements close to the downstream face (up to $2.0 \mathrm{~m}$ inside the dam), where the expansion occurs due to the presence of oxygen. The maximum dimension of the elements in the denser zone is 10 $\mathrm{cm}$. A linear joint was defined in the interfaces between the concrete dam and the rock.

\subsection{Definition of the expansions}

\subsubsection{ISA diffusion-reaction model}

The ISA develops in two stages: a primary reaction due to the oxidation of the iron sulfides in the aggregate (pyrrhotite) and a secondary reaction due to a sulfate attack of the products of the oxidation to the cement paste. The expansions due to ISA are obtained with the model proposed by the authors in [33], which is briefly described in this section. Further detail on the model may be found in the previous reference. 
The primary reaction is addressed by means of a diffusion-reaction model that takes into account the kinetic of the oxidation reactions of pyrrhotite and the oxygen diffusion in concrete. The evolution of the process depends of the oxidation of pyrrhotite in the aggregates, whose development is governed by the system of equations Eq. (1-4).

$$
\begin{gathered}
\frac{\partial\left[\mathrm{O}_{2}\right]}{\partial t}=\nabla^{2}\left(D\left[\mathrm{O}_{2}\right]\right)-g k_{2}\left[\mathrm{O}_{2}\right]\left[\mathrm{Fe}^{2+}\right] \\
\frac{\partial\left[\mathrm{Fe}_{1-x} S\right]}{\partial t}=-k_{4}\left[\mathrm{Fe}_{1-x} S\right]\left[\mathrm{Fe}^{3+}\right] \\
\frac{\partial\left[\mathrm{Fe}^{2+}\right]}{\partial t}=\delta k_{4}\left[\mathrm{Fe}_{1-x} S\right]\left[\mathrm{Fe}^{3+}\right]-k_{2}\left[\mathrm{O}_{2}\right]\left[\mathrm{Fe}^{2+}\right] \\
\frac{\partial\left[F e^{3+}\right]}{\partial t}=k_{2}\left[\mathrm{O}_{2}\right]\left[\mathrm{Fe}^{2+}\right]-\rho k_{4}\left[\mathrm{Fe}_{1-x} S\right]\left[\mathrm{Fe}^{3+}\right]
\end{gathered}
$$

where $x$ ranges between 0 and 0.125 and defines the stoichiometry of pyrrhotite, $g=0.25, \rho=8$ $2 x$ and $\delta=9-3 x$ are stoichiometrical coefficients of the reactions, $k_{2}$ and $k_{4}$ are kinetic coefficients of the iron sulfide oxidation reaction and $D$ is the oxygen diffusion coefficient in concrete.

The diffusion of the $\mathrm{Fe}^{2+}$ and $\mathrm{Fe}^{3+}$ will not be taken into account, because the proposed model considers the concrete as a homogeneous material, and the diffusion of the iron ions occur between aggregates and the mortar (process that could only be taken into account in a heterogeneous model like, for example, a meso-structural model).

Eq. (1) is obtained by applying Fick's Law. This equation allows taking into account the process of transport of oxygen from an external source (the atmospheric air) and its consumption by the chemical reactions inside the concrete. Expression Eq. 2 is the kinetics equation in terms of pyrrhotite consumption. Expression Eq. 3 is the continuity equation of the $\mathrm{Fe}^{2+}$ ion concentration in time. Likewise, expression Eq. 4 is the continuity equation of the concentration of $\mathrm{Fe}^{3+}$ ions.

The solution of this system is solved incrementally and iteratively, where the concentration of oxygen $\left(\left[\mathrm{O}_{2}\right]\right)$ is a global variable, whereas the concentrations of pyrrhotite $\left(\left[\mathrm{Fe}_{1-x} \mathrm{~S}\right]\right)$ and iron ions $\left(\left[\mathrm{Fe}^{2+}\right],\left[\mathrm{Fe}^{3+}\right]\right)$ are local variables.

The presence of water is an essential factor for the development of the oxidation reactions inside the concrete. In case of low water content in the environment of the pyrrhotite particles, oxidation will not occur. However, increasing the water content increases the number of pyrrhotite particles in contact with water, presenting conditions for the development of oxidation.

The kinetic coefficients are dependent on the water content $(\theta)$ in concrete through the expression Eq. (5).

$$
k_{i(\theta)}=k_{i(1)}\left[\frac{\theta \cdot e^{\beta}}{1+\theta\left(e^{\beta}-1\right)}\right]
$$

where $k_{i(l)}$ is the kinetic coefficient of reaction $i$ in satured concrete and $\beta$ is the parameters that controls the shape of the curve, that may range from a linear variation between the kinetic coefficient and the water content to variations with different curvatures depending on the value and sign of $\beta$.

The diffusion coefficient of oxygen is another parameter strongly dependent on the water content of the concrete. Experimental studies have shown that this coefficient is maximum in a dry 
concrete, leading to a very low value (near to zero) in saturated concrete. The diffusion coefficient is also dependent on the water content according to Eq. (6).

$$
D_{(\theta)}=D_{(0)}\left[1-\frac{\theta \cdot e^{\gamma}}{1+\theta\left(e^{\gamma}-1\right)}\right]
$$

where $\gamma$ is a parameter that controls the shape of the curve and $D_{(0)}$ is the diffusion coefficient of dry concrete.

The water content in the concrete is determined assuming that most of the dam is under saturated conditions due to the direct contact with the reservoir, with the exception of the area near the downstream face, where the water content decreases up to air humidity. For that Eq. (7) is used, which correlates the water content with the distance towards the surface exposed to the air $(\lambda)$.

$$
\theta_{(\lambda)}=\theta_{(0)}+\left(1-\theta_{(0)}\right) \cdot\left(1-e^{-\alpha \lambda}\right)
$$

where $\theta_{(0)}$ is the water content of the concrete surface exposed to the air, $\lambda$ is the distance of the point evaluated to the concrete surface and $\alpha$ is a parameter that controls the shape of the water content variation $(\theta)$ with $\lambda$.

The sulfuric acid from the oxidation of the iron sulfides in the aggregates in contact with the cement paste generates an acid attack that leads to the secondary reaction. This type of reaction was observed in tests performed on concrete samples from dams located in the Spanish Pyrenees that contain aggregates with phyrrotite. The tests revealed that the $\mathrm{pH}$ around the aggregates is lower than the $\mathrm{pH}$ in most of the paste. These findings indicate that the acid attack is caused by the aggregates.

The most relevant chemical reactions that occur were extensively studied for the external sulfate attack [35-37]. The sulfuric acid reacts first with the calcium hydroxide (portlandite) of the paste to form gypsum $\left(\mathrm{CaSO}_{4} .2 \mathrm{H}_{2} \mathrm{O}\right)$ and, afterwards, reacts with the different phases of non-diffusive calcium aluminates in the hydrated cement paste to generate secondary ettringite.

Ettringite formation depends on the transportation process of the sulfates from the inside of the aggregates towards the paste (a distance of centimeters). This process is faster than the oxidation of the iron sulfides, which depends on the oxygen diffusion inside the concrete in a distance of several meters in the case of dams. Therefore, the attack of the sulfates from the aggregates may be assumed as instantaneous if compared to the oxidation of pyrrhotite. Consequently, an additional kinetic treatment is not necessary. Campos et al. [33] develop the chemical reactions of the sulfate attack in more detail and justify why it is considered together with the oxidation processes of the primary reaction.

The evolution of volumetric expansion $(\Delta V / V)_{\text {w }}$ over time can be expressed as the function of pyrrhotite oxidation, as follows:

$$
\left(\frac{\Delta V}{V}\right)_{(t)}=\left(\frac{\Delta V}{V}\right)_{\infty} \cdot\left(\frac{\left[F e_{1-x} S\right]_{(0)}-\left[F e_{1-x} S\right]_{(t)}}{\left[F e_{1-x} S\right]_{(0)}}\right)
$$

where $(\Delta V / V)_{\infty}$ is the final or maximum volumetric expansion (obtained as the sum of the deformations due to the oxidation of the pyrrhotite and the formation of ettringite, considering as well a certain initial filling of the voids; further detail may be found in [33]) and $\left[\mathrm{Fe}_{1-x \mathrm{~S}} \mathrm{~S}\right]_{(0)}$ and $\left[\mathrm{Fe}_{1-x} \mathrm{~S}\right]_{(\mathrm{t})}$ are the initial pyrrhotite concentration and in the time t, respectively. The value of $\left[\mathrm{Fe}_{1-}\right.$ $\left.{ }_{x} S\right]_{(t)}$ is obtained by solving the system of equations Eq. (1-4). 


\subsubsection{AAR model}

The expansions due to AAR will be evaluated through the kinetic model proposed by Ulm et al. [26]. This model assesses the evolution of AAR with time depending on the temperature according to the differential equation Eq. (9).

$$
1-\xi(t)=\tau_{c(T)} \lambda_{(\xi, T)} \frac{\partial \xi_{(t)}}{\partial t}, \quad \lambda_{(\xi, T)}=\frac{1+e^{-\frac{\tau_{L(T)}}{\tau_{c(T)}}}}{\xi+e^{-\frac{\tau_{L(T)}}{\tau_{c(T)}}}}
$$

where $\xi$ is the extension of the reaction, $T$ is the absolute temperature, $t$ is the time, $\tau_{c}$ and $\tau_{L}$ are constant of the characteristic time and latency time, respectively. These time constants depend of the temperature according to the Eq. (10-11) based on the Arrhenius equation.

$$
\begin{gathered}
\tau_{c(T)}=\tau_{c\left(T_{0}\right)} e^{U_{c}\left(\frac{1}{T}-\frac{1}{T_{0}}\right)} \\
\tau_{L(T)}=\tau_{L\left(T_{0}\right)} e^{U_{L}\left(\frac{1}{T}-\frac{1}{T_{0}}\right)}
\end{gathered}
$$

where $T_{0}$ is the reference temperature, $U_{c}$ and $U_{L}$ are the activation constants of the characteristic time and latency time, respectively. From the tests performed by Larive [38], Ulm et al. [26] propose the following ranges for the activation constants: $U_{c}=5400 \pm 500 \mathrm{~K}$ and $U_{L}=9400 \pm$ $500 \mathrm{~K}$ (where $\mathrm{K}$ is Kelvin degrees).

In case of constant temperature, the analytical solution of the differential equation Eq. (9) is:

$$
\xi(t)=\frac{1-e^{-\frac{t}{\tau_{c}}}}{1+e^{-\frac{\left(t-\tau_{L}\right)}{\tau_{C}}}}
$$

Fig. 6 presents the curve given by Eq. (12), where the time corresponding to $\tau_{L}$ and to $\tau_{c}$ are shown.

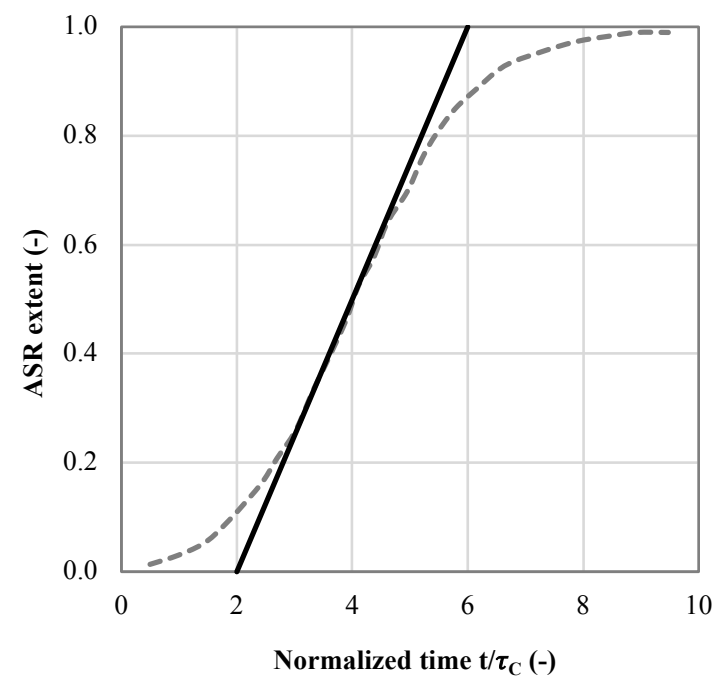

Fig. 6. Normalized isothermal expansion curve $\xi(t)$. Definition of $\tau_{L}$ and $\tau_{c}$. [26]

The expansion is considered to be proportional to the extension of the reaction, where $\left(\frac{\Delta V}{V}\right)_{\max }^{r a a}$ is the maximum volumetric expansion due to AAR. 


$$
\left(\frac{\Delta V}{V}\right)_{(t)}=\left(\frac{\Delta V}{V}\right)_{\max }^{r a a} \cdot \xi_{(t)}
$$

Once the temperature for each month of a typical year are known, the differential equation Eq. (9) may be integrated for each point of the mesh over time, obtaining with Eq. (13) the deformation for each point at different ages of the block. A reference temperature of 38 Celsius degrees was adopted since this value was used for the tests of Larive [38].

The temperature inside the dam depends on its boundary conditions (water temperature, environment temperature, speed of wind, incidence of sunlight, etc.) and the thermal properties of concrete (thermal conductivity, specific heat, among others). Based on the previous, the temperature in each point of the structure at different ages may be numerically obtained.

\subsection{Constitutive law for zero-thickness interface elements}

A convenient approach to simulate the cracks in finite element models (FEM) is using zerothickness interface elements with a nonlinear constitutive law that describes the cracking and allows considering the normal/shear coupling effect according to Mohr-Coulomb models. The literature reports several examples of interface laws that incorporate fracture concepts $[39,40]$ and examples of application in the analysis of dams [41, 42].

The constitutive law for zero-thickness interface elements used is based on the theory of elastoplasticity and incorporates fracture mechanic concepts [34]. The interface behavior is formulated in terms of the normal and shear components of the stresses on the interface plane and the corresponding relative displacements, which may be identified as crack openings.

The main characteristics of the plastic model are represented in Fig. 7. The initial loading (failure) surface $\mathrm{F}=0$ is given as a three-parameter hyperbola (see Eq. (13)).

$$
\mathrm{F}=\sigma_{\mathrm{T}}^{2}-\left(\mathrm{c}-\sigma_{\mathrm{N}} \tan \phi\right)^{2}+(\mathrm{c}-\chi \tan \phi)^{2}
$$

where tensile strength $\chi$ (the vertex of the hyperbola), asymptotic cohesion $c$ and asymptotic friction angle $\tan \phi$ are model parameters (see Fig. 7a). The model assumes that the crack appears when the stress in the interface plane reaches the condition of $\mathrm{F}\left(\sigma_{N}, \sigma_{T}\right)=0$, where $\sigma_{N}$ is the normal stress at the interface and $\sigma_{T}$ is the shear stress at the interface.
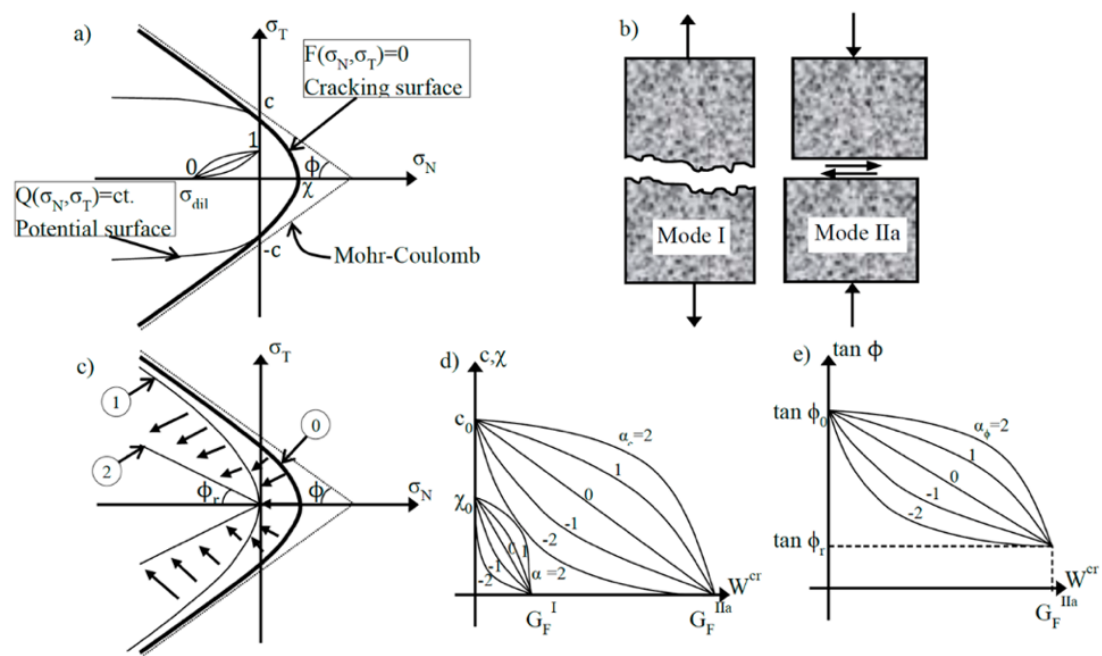

Fig. 7. Crack laws: a) hyperbolic cracking surface $\mathrm{F}$ and plastic potential Q; b) fundamental modes of fracture; c) evolution of cracking surface; d) softening laws for $\chi$ and c; e) softening law for $\tan \phi$ (reprinted from Carol et al. 2001, with permission). 
As the cracks appear, the loading surface begins to shrink due to the decrease in the main parameters according to evolution laws based on the work dissipated in fracture process $\left(W^{c r}\right)$. The increment of the work dissipated is calculated as the increment of plastic work, from which the frictional work is subtracted in compression. In order to control the evolution of $\mathrm{F}$, the model has two parameters that represent the classic energy of fracture in mode I, indicated as $G F^{I}$ (pure tension), and a second fracture energy under mode IIa defined under shear and high compression without dilatancy, denoted as $G F^{I I a}$ (schematically shown in Fig. 7b).

Under pure tension the final loading surface is given by a hyperbola with a vertex that is the origin in the stress space (curve "1" in Fig. 7c). Under a shear/compression load, the final state, reached when $c=0$ and $\tan \phi=\tan \phi_{r}\left(\tan \phi_{r}\right.$ represents the residual internal friction angle), is defined by a pair of straight lines representing the pure residual friction state (curve "2" in Fig. 7c). Additional parameters $\alpha_{x}, \alpha_{c}, \alpha_{\phi}$ control the softening curves evolution (for $\alpha_{x}=\alpha_{c}=\alpha_{\phi}=0$, the decrease is linear, Fig. $7 \mathrm{~d}$ and $7 \mathrm{e}$ ).

The model is associated in tension $(Q=F)$, but not in compression, where dilatancy vanishes progressively for $\sigma_{\mathrm{N}} \rightarrow \sigma^{\text {dil }}$ (Fig. 7a). Dilatancy is also decreased as the fracture process progresses, so that it vanishes for $W^{\mathrm{cr}}=G_{\mathrm{f}}^{\text {IIa }}$. The dilatancy decay functions also include shape parameters $\alpha_{\sigma}{ }^{\text {dil }}$ and $\alpha_{c}{ }^{\text {dil }}$ (also linear decay for zero values of shape parameters). A more detailed description of the interface law may be found in $[34,43,44]$.

The elastic stiffness matrix is diagonal with constant $\mathrm{K}_{\mathrm{N}}$ (normal interface elastic stiffnesses) and $\mathrm{K}_{\mathrm{T}}$ (tangential interface elastic stiffnesses) values, which can be regarded simply as penalty coefficients. This means that their values should be as high as possible. The upper bound for these values must be set as a compromise between the added elastic compliance and the numerical instability found for very high values (leading to very large trial stresses).

This model was satisfactorily applied to reproduce concrete meso-structures and other materials $[43-48,21]$. Recently, these interface elements were applied in the structural analysis of a gravity dam [49].

\section{NUMERICAL RESULTS}

\subsection{Results of the expansion models}

\subsubsection{Expansions due to ISA}

The diffusion-reaction model described in section 4.2.1 was applied to obtain the expansions due to ISA. Table 1 presents the parameters used in the kinetic model assuming that $\mathrm{Fe}^{3+}$ is the main oxidant of the iron sulfides. Notice that the initial concentration of iron sulfides was estimated based on the FRX analysis of a sample from the dam. Further detail on how these parameters were determined may be found in [33].

Table 1. Parameters adopted for the ISA diffusion-reaction model.

\begin{tabular}{|c|c|c|c|c|c|c|c|c|c|}
\hline \multicolumn{3}{|c|}{ moles $/ \mathrm{m}^{3}$} & \multicolumn{2}{|c|}{$\mathrm{m}^{3} /($ mol.s $)$} & $\mathrm{m}^{2} / \mathrm{s}$ & \multirow{2}{*}{$\theta_{0}$} & \multirow[b]{2}{*}{$\alpha$} & & \multirow[b]{2}{*}{$y$} \\
\hline$\left[\mathrm{O}_{2}\right]_{\mathrm{atm}}$ & {$\left[\mathrm{Fe}_{1-\mathrm{x}} \mathrm{S}\right]_{0}$} & {$\left[\mathrm{~F}^{2+}\right]_{0}$} & $\mathbf{k}_{2}$ & $\mathbf{k}_{4}$ & $\mathbf{D}_{(0)}$ & & & & \\
\hline 9.26 & 375.00 & 2.00 & $1.58 .10^{-7}$ & $2.85 .10^{-11}$ & $5.10^{-7}$ & 0.85 & 0.5 & -1.4 & 0.3 \\
\hline
\end{tabular}

The ratio $(\Delta \mathrm{V} / \mathrm{V})_{\mathrm{t}}$ was estimated using expression Eq. (8), by assuming that all iron sulfides had reacted. Fig. 8 presents a cross-section of block 5 with the evolution over time of the expansions due to ISA, assuming a maximum deformation of $6 \mathrm{~mm} / \mathrm{m}\left((\Delta \mathrm{V} / \mathrm{V})_{\infty}=0.018\right)$. The results indicate that the ISA develops in an area close to the downstream face, without any signs of expansion in the interior of the dam. 


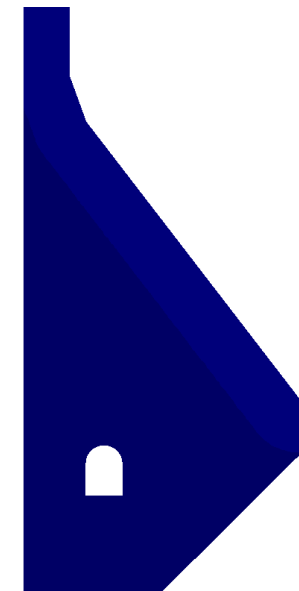

10 years

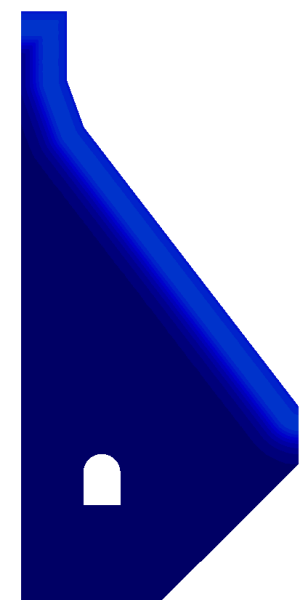

20 years

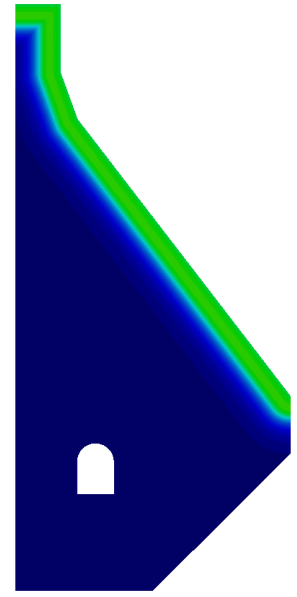

30 years

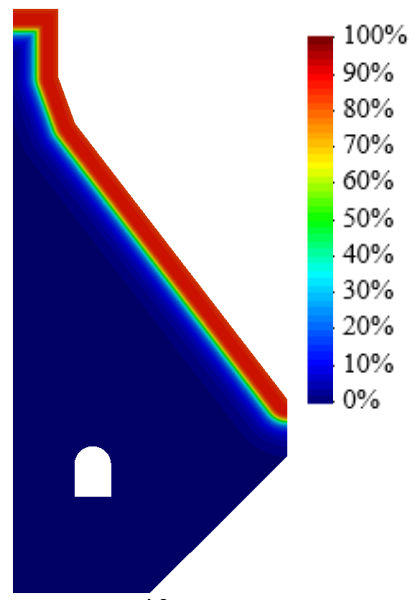

40 years

Fig. 8. Evolution of the expansions due to ISA (\%).

\subsubsection{Expansions due to AAR}

The kinetic model proposed by Ulm et al. [26] and previously described in section 4.2.2, requires a thermal analysis to determine the average monthly temperature. For that, the code DRACFLOW developed at the Department of Civil and Environmental Engineering at UPC was used since solves several diffusion problems such as the heat diffusion. Table 2 presents the thermal properties adopted for the thermal study.

Table 2. Parameters adopted for the thermal characterization of concrete.

\begin{tabular}{|c|c|c|c|}
\hline $\begin{array}{c}\text { Thermal conductivity } \\
\mathbf{W} /\left(\mathbf{m}^{2}{ }^{\circ} \mathbf{C}\right)\end{array}$ & $\begin{array}{c}\text { Specific heat } \\
\mathbf{J} /\left(\mathbf{K g}^{\circ} \mathbf{C}\right)\end{array}$ & $\begin{array}{c}\text { Specific weight } \\
\left(\mathbf{K g} / \mathbf{m}^{3}\right)\end{array}$ & $\begin{array}{c}\text { Convection coefficient } \\
\mathbf{W} /\left(\mathbf{m}^{2}{ }^{\circ} \mathbf{C}\right)\end{array}$ \\
\hline 2.5 & 1000 & 2500 & 20.63 \\
\hline
\end{tabular}

For the calculations, the soil is considered adiabatic and the temperature of water is defined in the nodes of the mesh that would be in contact with the reservoir. The heat transportation between the concrete and air is considered by applying flows imposed in the faces of the elements of the mesh in contact with the surface. These fluxes are obtained from the product between the convection coefficient and the difference of temperature between concrete surface and air. An initial temperature of the concrete was defined and, subsequently, the boundary conditions were applied each month until the annual cycle of temperatures is obtained. This way, the average temperatures for each point of the mesh and each month of the year may be found.

Fig. 9 presents the temperature calculated in block 5 for four months of the year, as an example. The results show that the interior of the dam does not present significant changes in temperature over the year, whereas the regions close to the faces of the dam experience variations of temperature from $0^{\circ} \mathrm{C}$ in the winter to $16^{\circ} \mathrm{C}$ in the summer. 

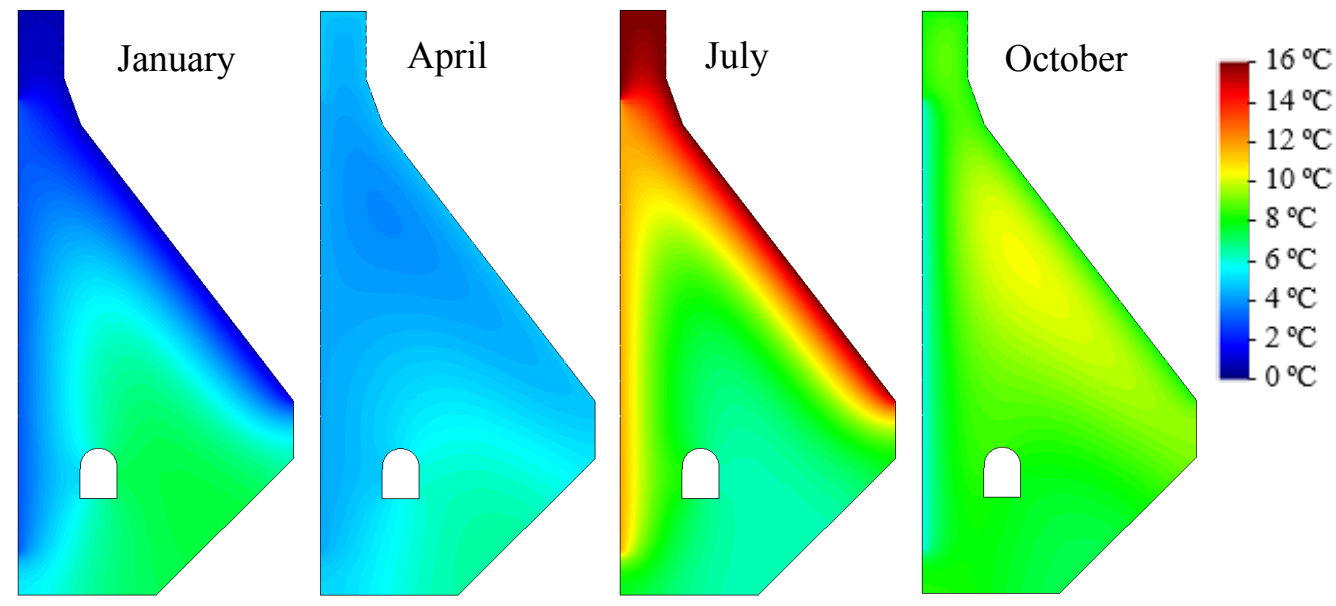

Fig. 9. Average monthly temperatures in block 5 .

Given that no experimental data are available of the AAR in the concrete of the dam, an inverse analysis is conducted to determine the other parameters of the model. Table 3 presents the parameters adopted for the AAR kinetic model. The ratio $(\Delta \mathrm{V} / \mathrm{V})_{\mathrm{t}}$ was estimated using expression Eq. (13). The maximum deformation is set to $2.8 \mathrm{~mm} / \mathrm{m}\left(\left(\frac{\Delta V}{V}\right)_{\max }^{r a a}=0.0084\right)$, which leads to vertical displacements in the gallery similar to those measured at the dam. Notice that the gallery is not influenced by the ISA.

Table 3. Parameters adopted for the AAR kinetic model.

\begin{tabular}{|c|c|c|c|c|}
\hline $\mathbf{T}_{\mathbf{0}}\left({ }^{\circ} \mathbf{C}\right)$ & $\mathbf{U}_{\mathbf{c}}(\mathbf{K})$ & $\mathbf{U}_{\mathbf{L}}(\mathbf{K})$ & $\boldsymbol{\tau}_{\mathbf{c}\left(\mathbf{T}_{\mathbf{0}}\right)}$ (days) & $\boldsymbol{\tau}_{\mathbf{L}\left(\mathbf{T}_{\mathbf{0}}\right)}$ (days) \\
\hline 38 & 5400 & 9700 & 387 & 422 \\
\hline
\end{tabular}

Fig. 10 presents the evolution over time of the expansions due to RAA in the cross-section of block 5 . The results show that the expansion begins in the area near to the downstream face due to the higher temperatures in the summer, which accelerate the reactions, and develops to the entire dam more uniformly than in the case of the ISA, which is a more localized reaction. Nevertheless, the results indicate a certain delay in the development of the reaction in the area below the gallery (see evolution in Fig. 10).

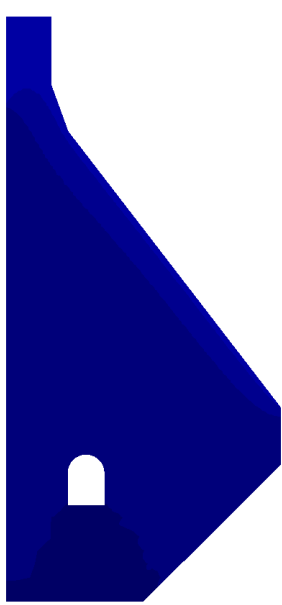

10 years

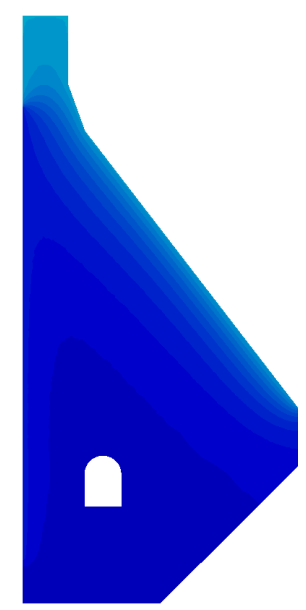

20 years

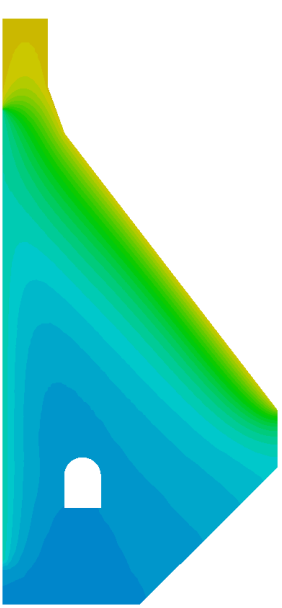

30 years

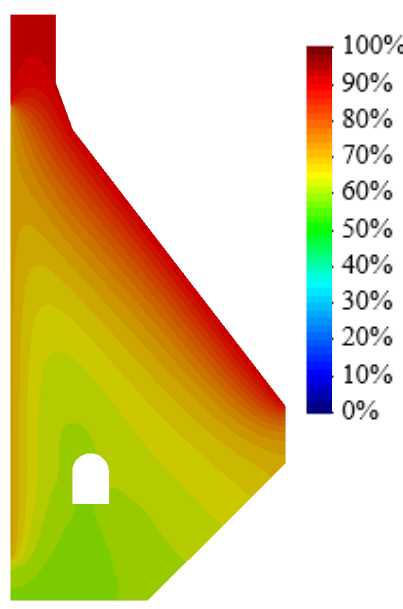

40 years

Fig. 10. Evolution of the expansions due to AAR (\%). 


\subsubsection{Expansions due to ISA and AAR}

The joint implementation of both expansive reactions leads to certain uncertainties, since it is not clear how one process may influence the evolution of the other. A reasonable hypothesis is to assume that the predominant deformation is the one generated by the most expansive reaction. Hence, the products of the reaction less expansive would fill the voids and cracks caused by the most expansive reactions. Such assumption does not imply the sum of the expansions of both reactions.

Fig. 11 presents the evolution of the expansions of both reactions (in $\mathrm{mm} / \mathrm{m}$ ) in block 5 . The results indicate that the early expansions are located near the downstream face and are mainly due to the ISA, whereas the expansions due to the AAR appear later and affect the rest of the dam.

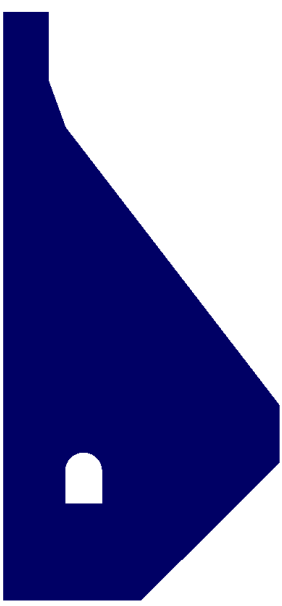

10 years

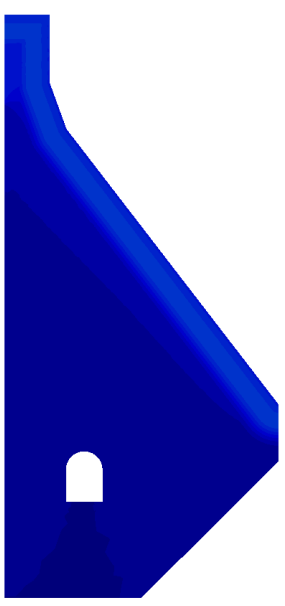

20 years

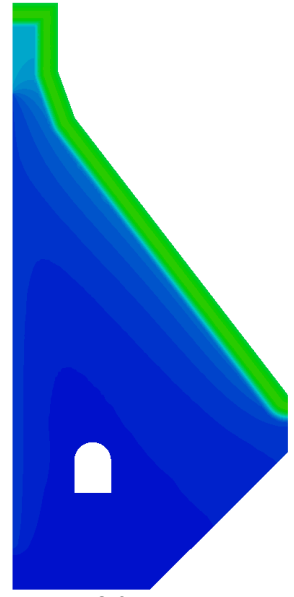

30 years

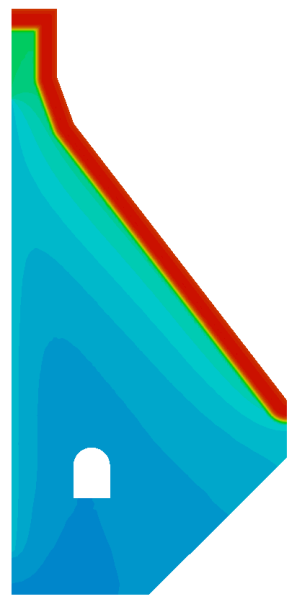

40 years

Fig. 11. Evolution of the expansions in block 5 due to ISA and AAR $(\mathrm{mm} / \mathrm{m})$.

Fig. 12 shows the distribution of the expansions due to ISA and AAR from the upstream face to the downstream face of a horizontal cross-section located approximately at mid-height of block 5 for different ages of the numerical simulation. The difference between the downstream face and the upstream face is clear in Fig. 12. In subsequent sections (section 5.3), the results of the nonlinear analysis of block 5 of the dam are presented and the discussion of the joint action of the ISA and AAR is resumed.

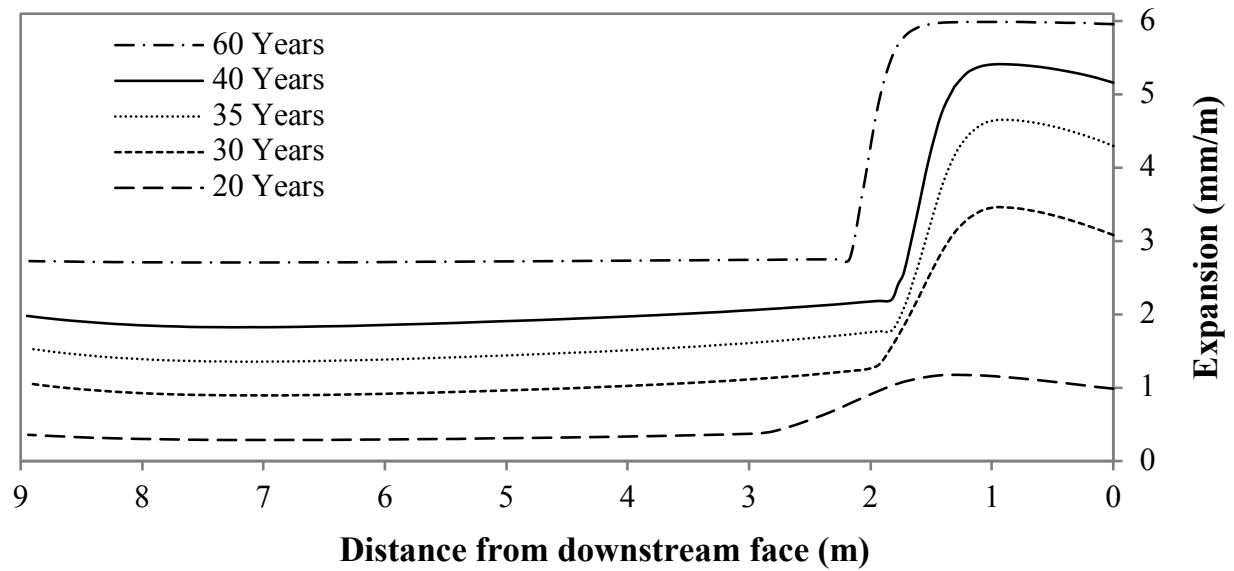

Fig. 12. Distribution of the expansions in a section a mid-height of block 5 due to the ISA and AAR at different ages of the numerical simulation. 


\subsection{Linear analysis of the concrete dam}

In general, the structural analysis of gravity dams with straight form in ground plant may be satisfactorily conducted through 2D model under plain strain conditions since their behavior can be assumed similar to a cantilever. The expansions in the concrete generate compressions in the longitudinal direction of the dam. Nevertheless, the high horizontal displacements registered in the central blocks of the dam suggest that the expansions may cause an arch effect that would contribute to increase the horizontal displacements of the structure. Therefore, besides the 2D modelling of certain blocks, a 3D numerical analysis of the concrete dam was also performed. The results of the linear behavior of both simulations are presented subsequently.

In the previous section, the distribution of the expansions due to the joint effect of the ISA and AAR for different ages obtained through the numerical models was presented (see Fig. 12). For the purpose of the linear calculations of the 3D and 2D meshes, the simplified distribution of the deformations presented in Fig. 13 was assumed. Notice that a constant distribution with a value of $\varepsilon_{\mathrm{a}}=1.62 \mathrm{~mm} / \mathrm{m}$ was adopted for the deformations due to the AAR, whereas for the area near the downstream face (with a thickness of $\delta=1.5 \mathrm{~m}$ ), whose surface is exposed to the air, a constant deformation of $\varepsilon_{b}=5 \mathrm{~mm} / \mathrm{m}$ is applied. The transition between both deformations is linear along a distance of $0.5 \mathrm{~m}$. As shown in Fig. 13, the adopted values correspond to a simplified distribution of the deformations at an age ranging from 35 and 40 years of the numerical simulation previously presented in Fig. 12. In the areas of concrete located below the level in contact with air, a uniform distribution with a value of $\varepsilon_{\mathrm{a}}=1.62 \mathrm{~mm} / \mathrm{m}$ is considered, which correspond to AAR.

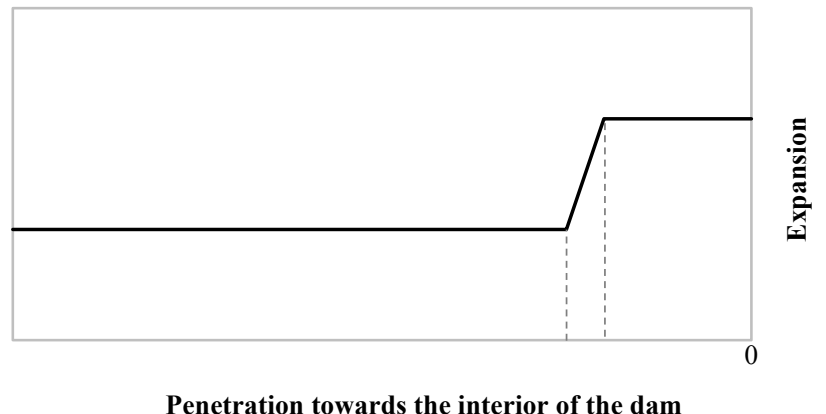

Fig. 13. Simplified deformation distribution due to expansion depending on the penetration from a surface exposed to oxygen towards the interior of the dam.

This distribution was applied to all blocks of the dam, assuming that the expansions are a global phenomenon, which is the hypothesis suggested in some of the previous studies.

The material parameters for the modelling take the following values: Young modulus of $20 \mathrm{GPa}$ and $70 \mathrm{GPa}$ for the concrete and the rock, respectively, and a Poisson coefficient of 0.2 for both materials. The values of the stiffness coefficients defined for the 3D modelling of the interface elements between the blocks of the dam are $\mathrm{K}_{\mathrm{n}}=10^{9} \mathrm{KN} / \mathrm{m}^{3}$ (this high value is defined to simulate a perfect contact between blocks) and $\mathrm{K}_{\mathrm{t}}=10^{5} \mathrm{KN} / \mathrm{m}^{3}$ (the influence of this parameter in the displacements is not relevant). In terms of the boundary conditions of the soil, the horizontal displacement is restrained in the sides and the vertical displacement is restrained at the bottom (see Fig. 5).

Regarding the actions, first the self-weight and the hydrostatic pressure are applied and then the expansions are included as imposed deformations at the nodes of the mesh (in an equivalent manner to the case of increments of temperature). In the several examples calculated, the displacements analyzed correspond to the nodes of the mesh located the closest to the real location of the measuring points at the crest of the dam. 
Fig. 14 presents the horizontal and vertical displacements calculated in the $3 \mathrm{D}$ simulation (continuous line) and in the 2D meshes in blocks 4, 5 and 6 (points). The results indicate that the calculated displacements present the same tendency as the corresponding displacements measured at the dam and shown in Fig. 2c and Fig. 2d, although the values are lower than the ones registered.
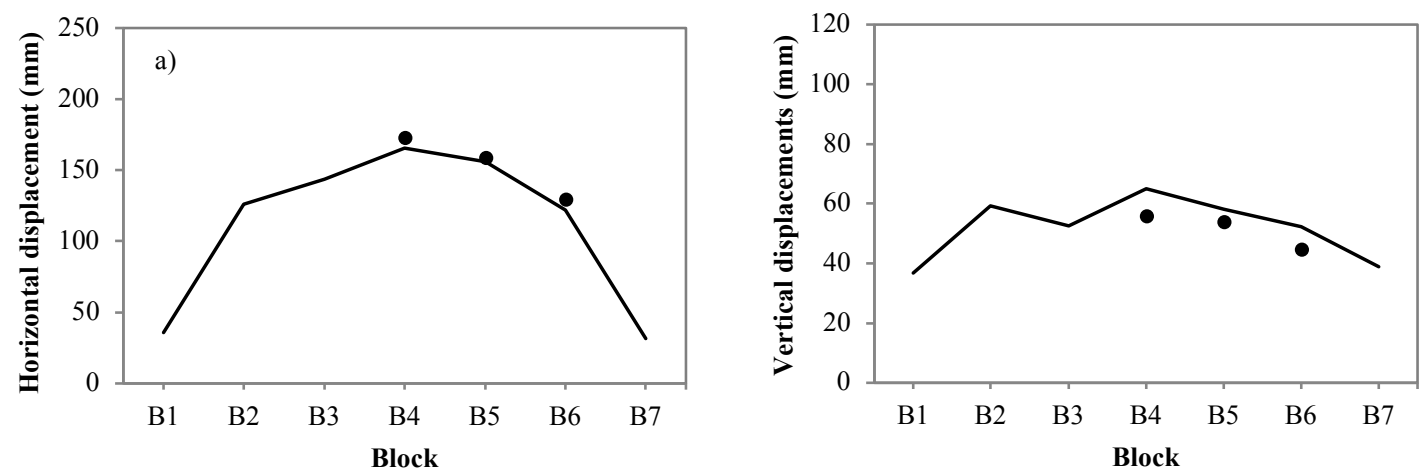

Fig. 14. Horizontal (a) and vertical (b) displacements calculated at the crest of the dam in the 3D (continuous line) and 2D (points).

The 3D simulation allowed evaluating the displacements in all blocks, considering as realistically as possible, all the constraints and interactions between blocks. The results indicate that the displacements calculated for blocks 4, 5 and 6 are very similar to those obtained with the 2D plain strain model. This confirms that the 2D simulation under plain strain conditions represents a valid simplification for the study of these blocks affected by internal expansions.

The calculated displacements under the assumption of a linear behavior of the materials yielded displacements that are qualitatively similar to those registered. However, as expected, the values are significantly lower due to the limitations of the linear analysis that does not consider the material degradation nor the contribution of the crack opening, as shown in subsequent sections.

\subsection{Non-linear analysis of the block 5}

In the past years, several horizontal cracks were detected in the shafts of the pendulum system up to a depth of $5.0 \mathrm{~m}$ from the crest (see Fig.20 in subsequent sections). The cracking may have a noticeable effect in the displacements registered in the dam, as previously reported by the authors [49].

The contribution of the cracking to the displacements is evaluated through the non-linear analysis of block 5. For that purpose, horizontal interface elements were defined in the discretization of the block (see Fig. 15b) at a distance of $0.5 \mathrm{~m}$ in the upper part of the dam. This distance corresponds to the average crack spacing observed in the shafts of the pendulum system. Interface elements were also incorporated to the lower part of the block according to the location and direction of construction joints (see Fig.15a) that are weak planes susceptible of cracking (the joints in the lowest part of the block, which are only affected by the uniform expansion due to AAR, have not been included in the model). The construction joints in the upper part of the dam are also inclined, however they are represented horizontally in the model according to the cracking observed in the dam. A 2D mesh was generated for block 5 as shown in Fig. 15 b. 

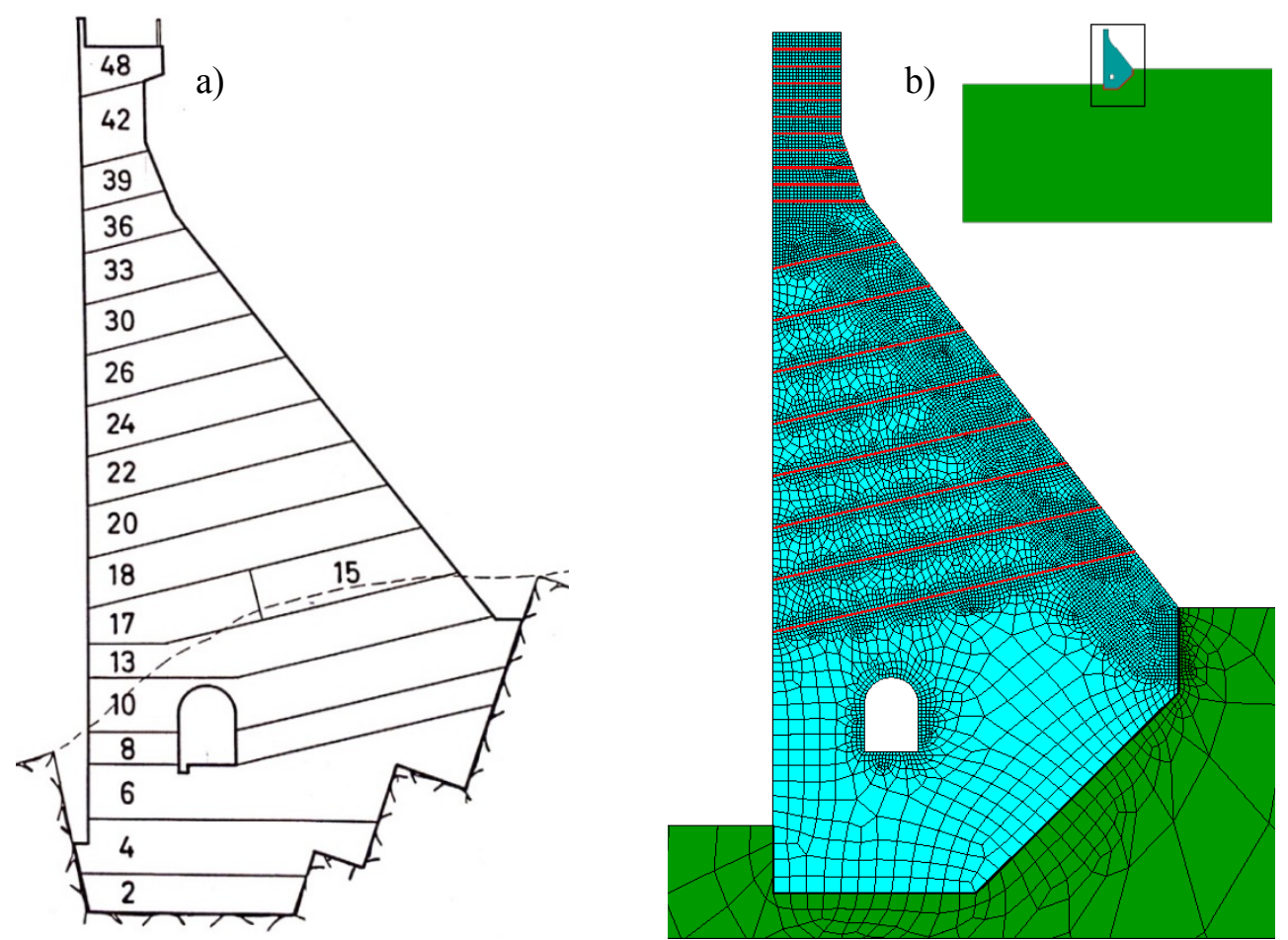

Fig. 15. a) Profile of the casting stages and b) finite element mesh of block 5 .

The same parameters of the linear calculations presented in section 5.2 are used for the continuum. The behavior of the joints is defined according to the non-linear constitutive law described in section 4.3. The tensile strength of the interface elements was set to $2.0 \mathrm{MPa}$. Stiffness constants and other model parameters take the following values: $K_{N}=K_{T}=10^{9} \mathrm{KN} / \mathrm{m}^{3}$, $\tan \phi_{0}=0.80$, $\tan \phi_{r}$ $=0.40, c_{0}=14 \mathrm{MPa}, G F^{I}=0.12 \mathrm{KN} / \mathrm{m}, G F^{I I a}=10 \mathrm{GF}^{\mathrm{I}}, \sigma_{\text {dil }}=40 \mathrm{MPa}$, with the rest of the parameters equal to zero. The distribution and evolution over time of the deformations due to the expansive reactions (see section 5.1) is considered in the model by a kinetic model for ASI (described in section 4.2.1 and developed in detail in Campos et al. [33] and a kinetic model for AAR proposed by Ulm et al. [26] and described briefly in section 4.2.2.

The mechanical response of block 5 is analyzed for two situations. In the first one, the deformation is mainly due to the most expansive reactions and that varies according to Fig. 11 and Fig.12. The second situation assumes that the deformations is the superposition of both reactions. The degree of superposition is unknown but the real situation would never reach values higher than the addition of both expansions (this unrealistic assumption was made in order to delimit the highest value). Therefore, two hypotheses are evaluated:

$$
\begin{aligned}
& \text { Hypothesis } 1(\mathrm{H} 1): \varepsilon_{(t)}=\max \left(\varepsilon_{(t)}^{A S I}, \varepsilon_{(t)}^{A A R}\right) \\
& \text { Hypothesis } 2(\mathrm{H} 2): \varepsilon_{(t)}=\left(\varepsilon_{(t)}^{A S I}+\varepsilon_{(t)}^{A A R}\right)
\end{aligned}
$$

where: $\varepsilon_{(t)}$ is the final expansion, $\varepsilon_{(t)}^{A S I}$ and $\varepsilon_{(t)}^{A A R}$ are the expansions due to ASI and AAR for a time $t$, respectively.

Fig. 16 shows the displacements registered at the dam and the ones yielded by the model with nonlinear joints for hypotheses $\mathrm{H} 1$ and $\mathrm{H} 2$. The curves reveal that considering the cracking in the model increases of the horizontal and vertical displacements in comparison with the linear analysis (see Fig.14). In case of hypothesis H1, the displacement yielded by the model reach values close to real displacements. 
In terms of the horizontal displacements, hypothesis $\mathrm{H} 1$ leads to an increase of $5 \mathrm{~cm}$ in 2011 with respect to the displacements of the linear analysis (see Fig.16a). The horizontal displacements for hypothesis $\mathrm{H} 2$ increase significantly with no tendency to stabilization (see Fig.16a).

The vertical displacements increase around $3 \mathrm{~cm}$ and $4 \mathrm{~cm}$ with respect to the linear analysis for hypothesis $\mathrm{H} 1$. These values are higher for hypothesis $\mathrm{H} 2$; however, they are not of the magnitude observed for the horizontal displacements. In addition, Fig. $16 \mathrm{~b}$ also reveals that the values yielded by the model are consistent with the vertical displacements measured at the gallery (are without expansion due to ISA and without joints in the model).
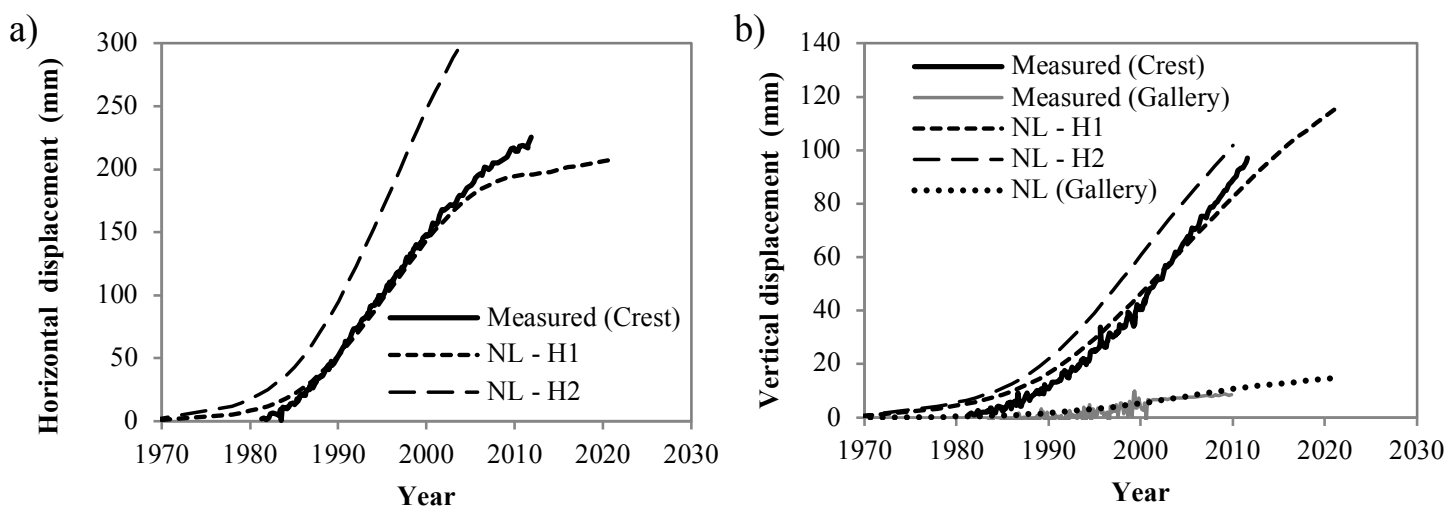

Fig. 16. Evolution of the horizontal (a) and vertical displacements (b) measured at the dam and calculated with non-linear models (NL) at the crest and in the gallery (vertical displacements).

\section{VALIDATION OF THE HYPOTHESES}

\subsection{Growth rate of the displacements}

The evolution over time of the displacements registered at the dam were presented in previous sections. However, at this point, it may be interesting to evaluate the increment of the displacements per year. Fig. 17 shows the growth rate of the horizontal and the vertical displacements in each block in terms of mm per year.
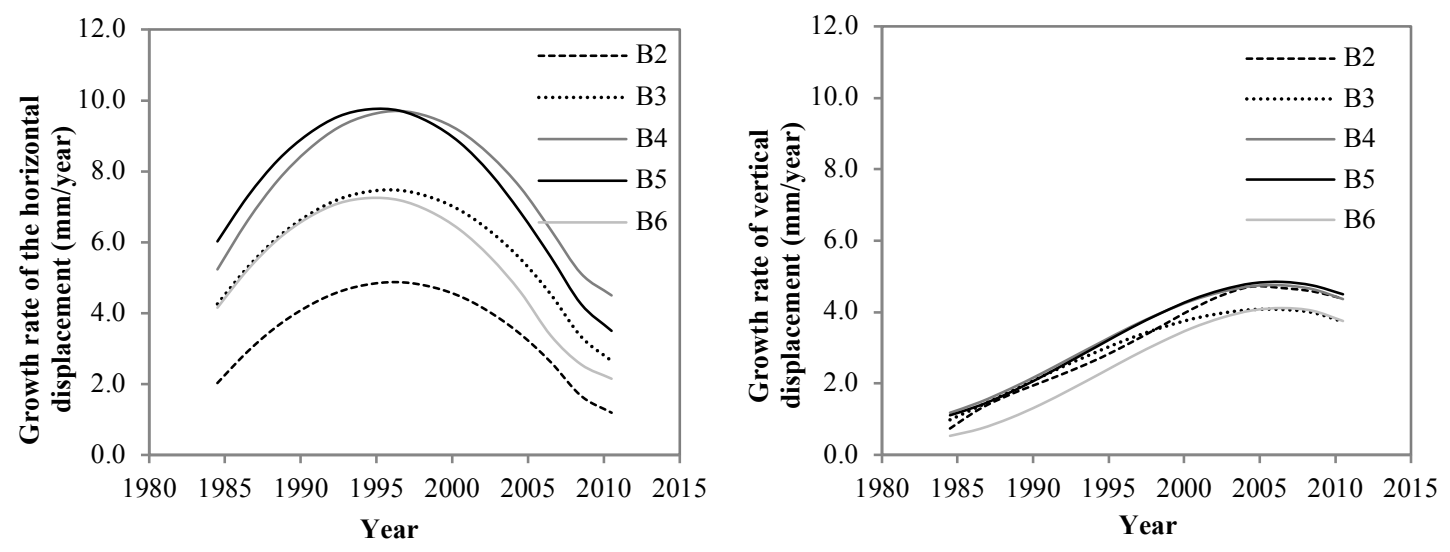

Fig. 17. Evolution of the growth rate ( $\mathrm{mm} /$ year) for: $\mathrm{a})$ horizontal and $\mathrm{b}$ ) vertical displacements.

Figure 17a shows that the growth rate of the horizontal displacements starts shortly before 1985 (after the equipment to measure displacements was installed in the dam) and reaches its peak approximately in 1995, where maximum values of the growth rate are observed in all blocks. In the case of blocks B4 and B5, the growth rate reached values of $10 \mathrm{~mm} /$ year. From 1995 onwards, the growth rate decreases gradually and proportionally to the geometric characteristics of each 
block. Notice that the maximum growth rate represents the turning point in the evolution of the displacements in Fig. 2a, which corresponds to 300-320 months after the dam started operating.

The curves in Figure $17 \mathrm{~b}$ indicate that the vertical displacements are experiencing a similar evolution to the horizontal displacements but with a higher amplitude of the curve and lower absolute values. Notice that the maximum growth rate occurs around 2006 and the maximum values are slightly below $5 \mathrm{~mm} /$ year for blocks B4 and B5. The turning point in the evolution of the displacements registered corresponds to 430 months after the dam started operating.

\subsection{Influence of the reaction kinetics in the displacements of the dam}

The curves described in the previous section highlight an interesting phenomenon. The process generating the horizontal displacements occurred before and at a higher rate than the process causing the vertical displacements. Fig. 11 in section 5.1.3 reveals that the first expansions occur in the areas close to the downstream face due to ISA and the subsequent expansion caused by the AAR appear in the rest of the dam. This difference in the kinetics between both reactions is consistent with the behavior detected in the evolution rate of the horizontal and vertical displacements in Fig. 17.

This hypothesis was confirmed with scanning electron microscopy (SEM) conducted on samples extracted from the dam, which revealed the presence of ettringite associated to the ISA and gel from the AAR. In particular, Fig. 18 shows ettringite crystals covered by the gel, which indicates that the gel was formed after the ettringite.
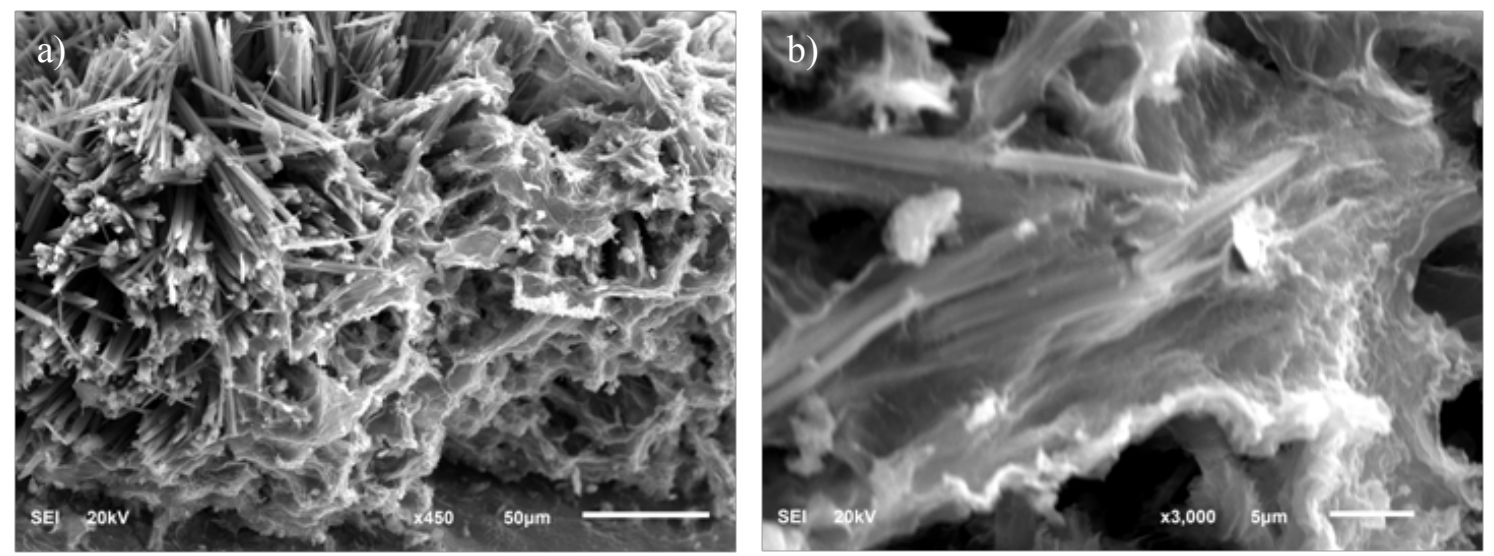

Fig. 18. SEM of sample extracted from the dam: a) ettringite crystals and gel of the AAR, b) detail of the gel covering the ettringite crystals.

Experimental studies dating from 1993 indicate that only small amounts of gel of the AAR were found in the cores drilled from the dam. This may be attributed to the kinetics of the reaction, which requires more time to develop. Therefore, at that time, the reaction had not advanced significantly. This is consistent with the vertical displacements registered in the gallery, where the non-recoverable displacements are detectable from 1995 (see block 5 in Fig. 16).

\subsection{Extent of expansions}

The 2D and 3D linear calculations in section 5.2 were obtained by defining the same deformation law in all blocks. The horizontal and vertical displacements at the crest of the dam yielded by the model (see Fig. 14) are qualitatively consistent with the tendency registered in each block of the dam (see Fig. 2c and Fig. 2d). However, the magnitude of the displacements is lower due to the limitations of the linear analysis (the influence of the cracking in the results is presented in section 5.3). Despite the above, the tendency observed indicates that the expansions are generalized and similar in all blocks, being the different geometry of the blocks the cause of the differences in 
magnitude. The annual increments of horizontal and vertical displacements shown in Fig. 17 support this idea.

\subsection{Influence of the cracking}

The non-linear analyses in section 5.3 show that considering cracking in the model increases the horizontal and vertical displacements in block 5, which results in values that are close to the displacements registered in the dam.

Fig. 19 shows the evolution of the cracking for hypothesis H1 for different ages in terms of released energy during the fracture process. This amount of energy is represented by the thickness of the line in the joints. Notice that the red stretches represent loaded areas of the joint where the crack is active, whereas the blue stretches correspond to elastic unloaded cracks.

Several cracks are detected close to the crest, many of them connected to the face of the dam. Cracking is also observed in the construction joints of the block, particularly in the internal part.

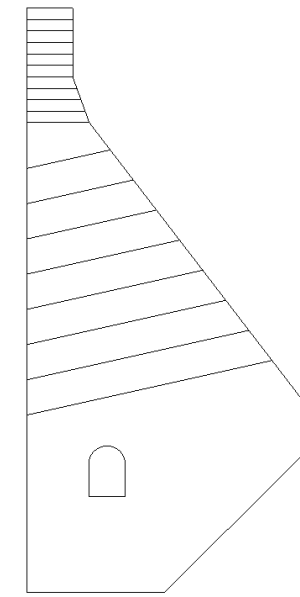

5 years

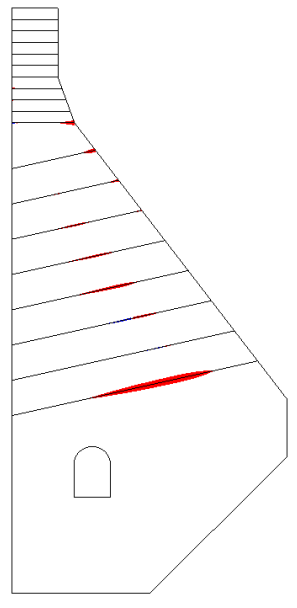

10 years

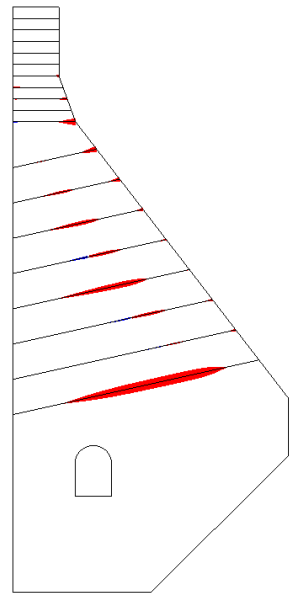

20 years

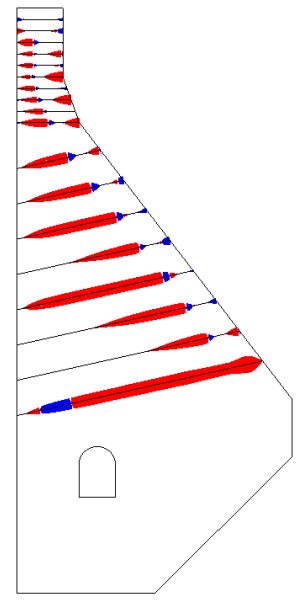

40 years

Fig. 19. Evolution of cracking in block 5 .

The cracking observed in the upper part (in the $5.0 \mathrm{~m}$ above) and their width are very similar to those detected in the dam (the numerical cracks vary between 1 and $4 \mathrm{~mm}$ and the ones measured range from 1 to $5 \mathrm{~mm}$ ). The evolution of horizontal cracking with time is also consistent with what was observed in the dam. According to Fig. 19, the main cracking appears after 20 years of construction, being significant at 40 years (this corresponds to year 2010). Photographic information dating from 1991 (age 20 years) is presented in Fig. 20a and Fig. 20c, showing two wells of the pendulum system with no cracking. However, the same wells in 2009 (age 38 years) present significant cracking (see Fig. 20b and Fig. 20b).

Additional internal cracks in the lower levels of the block may exist but cannot be confirmed since they are not connected with the faces of the dam. Given the distribution of expansions from the downstream to the upstream face (above the gallery where the two expansions occur, as shown in Fig. 12), compressive stresses appear close to the faces and tension stresses in inner part of the cross-section. Cracks appear when the stresses exceed the tensile strength of concrete and develop as shown in the joint elements in Fig.19. Also, the biaxial compressive stress state parallel to the surface formed due to the restrained in-plane expansion may lead to material detachment (delamination) in the downstream face if the stresses in this area are high. This stress distribution in the cross-section has been also reported by other authors [26, 13, 32]. 
Experimental studies conducted in 2011 in samples from the dam revealed more degradation in areas close to the downstream face (rather than internal areas of the dam). Even though no detachments are detected externally, beyond the common freeze-thaw cycles, further analysis is required regarding the effects of the biaxial compressive state.
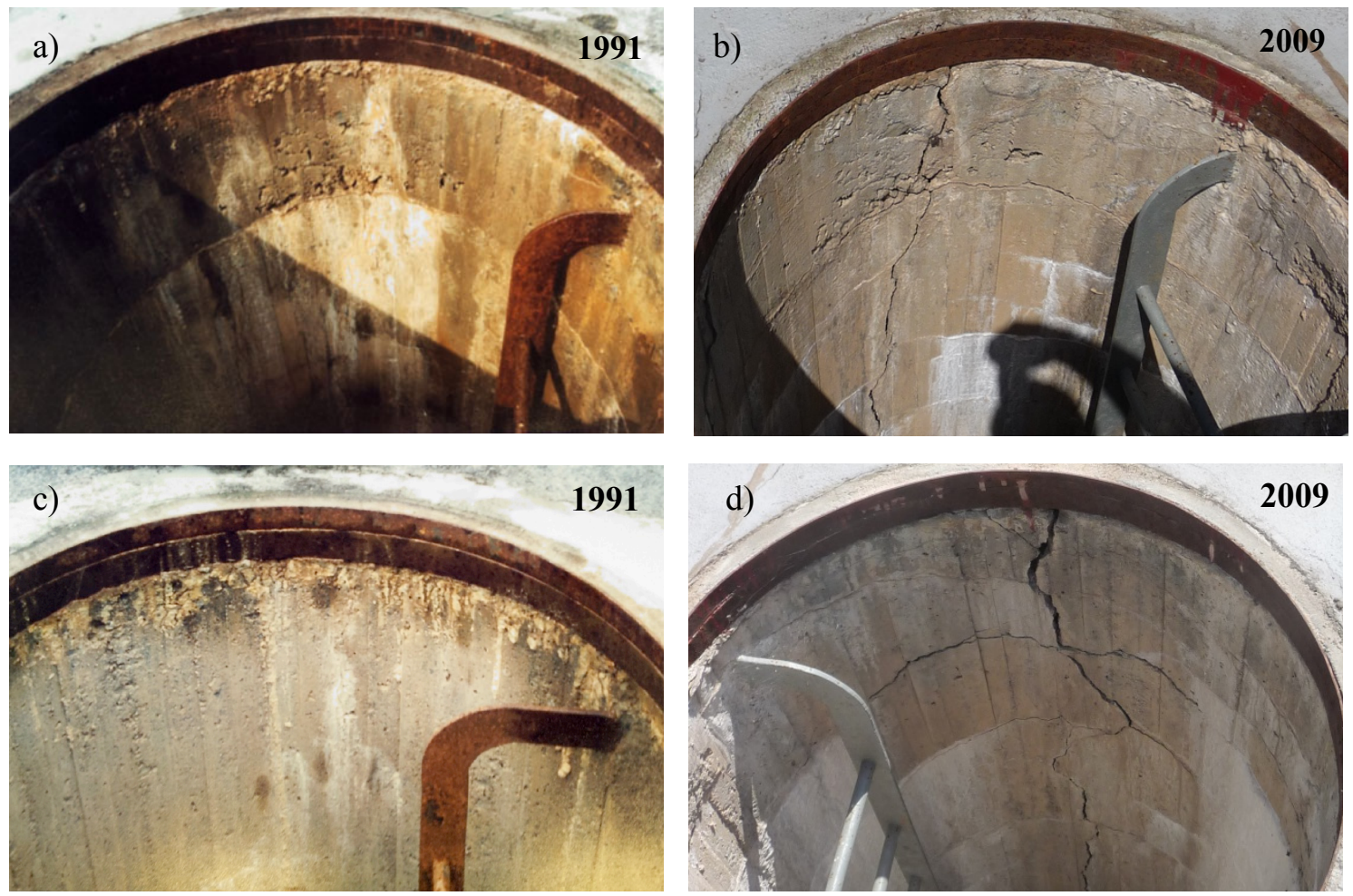

Fig. 20. Access points to the pendulum system: a) well 1 in 1991, b) well 1 in 2009, c) well 2 in 1991 and d) well 2 in 2009.

\subsection{Relation between expansive deformations and displacements at the crest}

Fig. 16 shows an evolution of displacements in the dam closer to the ones obtained with hypothesis $\mathrm{H} 1$ than with those yielded with hypothesis $\mathrm{H} 2$ (both hypothesis represent theoretically the limits values). Hypothesis $\mathrm{H} 1$, which is a reasonable assumption, fits the vertical displacements; however only fits the horizontal displacements up to the year 2000. Afterwards, the values decrease and remain below the displacements registered.

The situation that would best fit both displacements should consider a certain superposition of the effects caused by the ISA and AAR. This superposition would only be possible in the downstream face where the ISA takes place (see Fig. 8). The drills cored from the experimental study in 2011 exhibited gel from the AAR covering the ettringite needles caused by the ISA (see Fig. 18). Therefore, assuming a certain superposition of effects in the downstream face is possible, thus leading to an increase of the horizontal displacements if compared to the values calculated according to hypothesis $\mathrm{H} 1$.

\section{CONCLUSIONS}

This paper presents the real case of a concrete dam that exhibits high non-recoverable displacements caused by the confluence of two expansive reactions: an internal sulfate attack (ISA) and an alkali-aggregate reaction (AAR). The early diagnosis attributed the behavior of the dam only to an internal sulfate attack, however, the study over time of the behavior allowed its reformulation. 
Based on the results obtained through the numerical analyses, the following conclusions may be derived from the study:

- The numerical model yields results that are consistent with the diagnosis of a combined effect of an AAR that affects the dam globally and an ISA localized close to the downstream face.

- The kinetics of the reactions are different. The ISA is faster and generates expansions with higher unitary deformations. Furthermore, this reaction governs the horizontal displacements at the crest of the dam since the gradient is higher the downstream face than in the upstream face. The AAR is slower and the expansions are smaller in terms of deformations. This reaction is the main cause of the vertical displacements.

- An approximate order of magnitude of the expansions was determined with 2D and 3D linear models with a simplified deformation distribution. Furthermore, the results of the models revealed that the expansions were a global issue in the dam.

- The structural analysis considering joint elements in order to simulate cracking was essential to reproduce the cracks observed in the dam and include their contribution in the displacements, yielding a better fit of the values registered at the crest of the dam. This aspect was also paramount in the analysis of the dam in [50].

- A kinetic model for the ISA was also proposed by using a diffusion-reaction model that considers the oxygen transport into the concrete and its consumption by the oxidation reactions, thus determining the distribution and evolution of the volumetric deformations due to the ISA over time. A detailed description of this model may be found in [33].

The paper presents a singular case of a concrete dam that is affected by an ISA and AAR. This type of situation is scarcely documented in the literature and, thus, represents an interesting contribution to the dam engineering profession. In addition, the validation of the diagnosis is conducted through numerical simulation tools that may be applied to other cases.

\section{ACKNOWLEDGEMENTS}

The authors acknowledge the economic support provided by the Ministerio de Economía y Competitividad (Spain MEC) through the project BIA2013-49106-C2-1-R. Furthermore, the authors wish to thank Endesa Generación S.A. the invaluable economical and technical support over the years, in particular to Felipe Río and Francisco José Conesa. The Spanish Ministry of Economy and Competitiveness supported the first author through the scholarship FPU.

\section{REFERENCES}

[1] T.E. Stanton, Expansion of concrete through reaction between cement and aggregate. American Society of Civil Engineering, 66 (1940) 1781-1811.

[2] D.W. Hobbs, Alkali-silica reaction in concrete, Telford, Michigan, 1988.

[3] R.N. Swamy, Assessment and rehabilitation of AAR-affected structures, Cement Concrete Comp., 19(56) (1997) 427-440.

[4] P.K. Mehta, P.J. Monteiro, Concrete Microstructure, properties and materials, 3rd ed., McGraw-Hill, New York, 2006.

[5] I. Casanova, L. Agulló, A. Aguado, Aggregate expansivity due to sulfide oxidation-I. Reaction system and rate model, Cement Concrete Res., 26 (1996) 993-998.

[6] C. Ayora, J.S. Chinchón, A. Aguado, F. Guirado, Weathering of Iron Sulfides and Concrete Alteration: Thermodynamic Model and Observation in Dams from Central Pyrenees, Spain, Cement Concrete Res., 28(4) (1998) 591-603.

[7] S. Chinchón-Payá, A. Aguado, S. Chinchon, A comparative investigation of the degradation of pyrite and pyrrhotite under simulated laboratory conditions. Eng. Geol., 127 (2012) 75-80. 
[8] A. Tagnit-Hamou, M. Saric-Coric, P. Rivard, Internal deterioration of concrete by the oxidation of pyrrhotitic aggregates, Cement Concrete Res., 35 (2005) 99-107.

[9] F.P. Glasser, The stability of ettringite, in: K. Scrivener, J. Skalny (Eds.), International RILEM Workshop on Internal Sulfate Attack and Delayed Ettringite Formation, RILEM, 2004, p. 43-64.

[10] X. Brunetaud, L. Divet, D. Damidot, Impact of unrestrained delayed ettringite formation-induced expansion on concrete mechanical properties, Cement Concrete Res., 38(11) (2008) 1343-48.

[11] A. Shayan, G.W. Quick, Microscopic features of cracked and uncracked concrete railway sleepers, ACI Mater. J., 89 (1992) 348-361.

[12] A. Shayan, I. Ivanusec, An experimental clarification of the association of delayed ettringite formation with alcali-aggregate reaction, Cement Concrete Comp., 18 (1996) 161-170.

[13] V.E. Saouma, Numerical modeling of AAR, CRC Press/Balkema, Leiden, 2014.

[14] Z.P. Bazant, A. Steffens, Mathematical model for kinetics of alkali-silica reaction in concrete, Cement Concrete Res., 30(3) (2000) 419-428.

[15] A. Suwito, W. Jin, Y. Xi, C. Meyer, A mathematical model for the pessimum size effect of ASR in concrete, Concrete Science and Engineering 4(13) (2002) 23-34.

[16] S. Multon, A. Sellier, M. Cyr, Chemo-mechanical modeling for prediction of alkali-silica reaction (ASR) expansion, Cement Concrete Res., 39(6) (2009) 490-500.

[17] W. Puatatsananon, V.E. Saouma Chemo-Mechanical Micromodel for Alkali-Silica Reaction. ACI Mater. J., 110(1) (2013) 67-77.

[18] I. Comby-Peyrot, F. Bernard, P.I. Bouchard, F. Bay, E. Garcia-Diaz, Development and validation of a $3 \mathrm{D}$ computational tool to describe concrete behavior at mesoscale. Application to the alkali-silica reaction. Computational Material Science, 46(4) (2009) 1163-1177.

[19] C.F. Dunant, K.L. Scrivener, Micro-mechanical modelling of alkali-silica reaction-induced degradation using the AMIE framework. Cement Concrete Res., 40(4) (2010) 517-525.

[20] G. Xotta, K. Willam, E. Bombasaro, V. Salomoni, C. Majorana, Coupled Efects of Creep and AlkaliSilica Reaction in Concrete at the Meso-Scale. In: CONCREEP 10, 2015, p. 466-476.

[21] A.E. Idiart, C.M. López, I. Carol, Chemo-mechanical analysis of concrete cracking and degradation due to external sulfate attack: A meso-scale model, Cement Concrete Comp., 33(2), (2011), 411-423.

[22] G.A. Thompson, R.G. Charlwood, R.R. Steele, D.D. Curtis, Mactaquac generaring station intake and spillway remedial measures, In: ICOLD (Ed.) Eighteenth International Congress on Large Dams, Durban, 1994, p. 347-368.

[23] P. Léger, P. Côté, R. Tinawi, Finite element analysis of concrete swelling due to alkali-aggregate reactions in dams, Comput. Struct., 60(4) (1996) 601-611.

[24] J.P. Bournazel, M. Moranville, Durability of the concrete: The crossroad between chemistry and mechanics. Cement Concrete Res., 27(10) (1997) 1543-1552.

[25] M. Herrador, F. Martínez-Abella, R. Hoyo Fernández-Gago, Mechanical behaviour model for ASRaffected dam concrete under service load: formulation and verification, Mater. Struct., 42(2) (2009) 201212.

[26] F.-J. Ulm, O. Coussy, L. Kefei, C. Larive, Thermo-Chemo-Mechanics of ASR Expansion in Concrete Structures. ASCE Journal of Engineering Mechanics, 126(3) (2000) 233-242.

[27] K. Li, O. Coussy, Concrete ASR degradation: from material modeling to structure assessment, J. Concrete Science and Engineering, 4 (2002) 35-46.

[28] A. Sellier, E. Bourdarot, S. Multon, M. Cyr, E. Grimal, Combination of estructural monitoring and laboratory tests for assessment of alkali-aggregate reaction swelling: Application to gate structure dam, ACI Mater. J., 106(3) (2009) 281-290.

[29] E. Grimal, A. Sellier, Y. LePape, E. Bourdarot, Creep, shrinkage, and anisotropic damage in alkaliaggregate reaction swelling mechanism-Part I: A constitutive model. ACI Mater. J., 105(3) (2008) 227235. 
[30] C. Comi, U. Perego, Anisotropic damage model for concrete affected by alkali-aggregate reaction, Int. J. Damage Mech., 20(4) (2011) 598-617

[31] V. Saouma, L. Perotti, Constitutive model for alkali-aggregate reactions. ACI Mater. J., 103(3) (2006) 194-202.

[32] V. Saouma, L. Perotti, T. Shimpo, Stress Analysis of concrete Structures Subjected to AlkaliAggregate Reactions, ACI Struct. J., 104(5) (2007) 532-541.

[33] A. Campos, C. López, A. Aguado, Diffusion-reaction model for the internal sulfate attack in concrete, Constr. Build. Mat., 102 (2016), 531-540.

[34] I. Carol, P.C. Prat, C.M. López, Normal/Shear Cracking Model: Application to Discrete Crack Analysis, J. Eng. Mech.-ASCE, 123 (1997) 765-773.

[35] J. Skalny, J. Marchand, I. Odler, Sulfate Attack on Concrete, 10th ed. Spon Press, London, 2002.

[36] R. Tixier, B. Mobasher, Modeling of Damage in Cement-Based Materials Subjected to External Sulfate Attack. I: Formulation. J Mater Civil Eng, 15 (2003) 305-313.

[37] R. Tixier, B. Mobasher, Modeling of Damage in Cement-Based Materials Subjected to External Sulfate Attack. II: Comparison with Experiments. J Mater Civil Eng, 15 (2003) 314-322.

[38] C. Larive, Apports combines de l'experimentation et de la modélisation à la comprehension del'alcalireaction et de ses effets mécaniques, Doctoral thesis, Laboratoire Central des Ponts et Chaussées, Paris, 1998 (in French).

[39] H. Lotfi, P. Shing, Interface model applied to fracture of masonry structures, J. Struct. Eng.ASCE,120(1), (1994), 63-80.

[40] T. Stankowski, K. Runesson, S. Sture, Fracture and slip of interfaces in cementitious composites. I: Characteritics; II: Implementation, J. Eng. Mech.-ASCE, 119 (1993) 292-327.

[41] J. Hohberg, Concrete joints, Mechanics of geomaterials interfaces, eds. Selvadurai \& Boulton, Elsevier Science, 421-446, 1995.

[42] M. Azmi, P. Paultre, Three-dimensional analysis of concrete dams including contraction joint nonlinearity, Engineering Structures 24, 757-771 (2002).

[43] I. Carol, C.M. López, O. Roa, Micromechanical analysis of quasi-brittle materials using fracture interface elements, Int. J. Numer. Meth. Eng., 52 (2001) 193-215.

[44] C.M. López, I. Carol, A. Aguado, Meso-structural study of concree fracture using interface elements. I: numerical model and tensile behavior. Mater. Struct., 41 (2008) 583-599.

[45] C.M. López, I. Carol, A. Aguado, Meso-structural study of concrete fracture using interface elements. II: compression, biaxial and Brasilian test. Mater. Struct., 41 (2008) 601-620.

[46] A.E. Idiart, C.M. López, I. Carol, Modeling of drying shrinkage of concrete specimens at the mesolevel, Mater. Struct., 44(2) (2011) 415-435.

[47] A. Caballero, I. Carol, C.M. López, 3D meso-structural analysis of concrete specimens under uniaxial tension. Comput. Method Appl. M., 195(52) (2006a) 7182-7195.

[48] A. Caballero, I. Carol, C.M. López, New results in 3D meso-mechanical analysis of concrete specimens using interface elements, In: G. Meschke, R. de Borst, H. Mang, N. Bicanic (Eds.), Computational Modelling of Concrete Structures, EURO-C 2006 Conference. Taylor \& Francis Group; 2006b, p. 43-52.

[49] A. Campos, C. López, A. Blanco, A. Aguado, Structural Diagnosis of a Concrete Dam with Cracking and High Nonrecoverable Displacements, J. Perform. Constr. Facil., 30(5) (2016) 04016021. 